\title{
Sobre la teoría general unitaria del derecho procesal, algunos elementos a ser tenidos en cuenta para una historia de la disciplina para el ámbito hispanoamericano
}

\author{
Aram Zaldivar Rodriguez*
}

\section{INTRODUCCIÓN}

Hubo una moda académica no hace mucho tiempo en el ámbito del Derecho procesal dedicada con mucha energía a la defensa de una teoría general unitaria de la materia. Esta moda sirvió (y aún sirve) para hurgar en la disciplina con la voluntad de encontrar una teoría que fuera útil para separar el Derecho procesal de manera definitiva de otras ramas jurídicas. La apología de la teoría general del Derecho procesal, fue en buena parte, la herramienta utilizada para la convalidación de la "ciencia" del Derecho procesal. Aun cuando la utilidad de este empeño pueda resultar a algunos algo rara, lo cierto es que no deja de ofrecer espacios de reflexiones para seguir soñando con la anhelada justicia.

Existe un consenso más o menos asumido de manera general en los países de habla hispana, en que fue Niceto Alcalá-Zamora y Castillo, la figura fundamental en la difusión del pensamiento unitario del Derecho procesal. En estas letras, humilde homenaje a Niceto, he querido pues mirar aquellas circunstancias que seguramente tuvieron algún peso en la preferencia del profesor español por esta teoría. No solo pretendo aportar algunos elementos que sirvan a valorar la dimensión de esta interrogante hacia la cientificidad del Derecho procesal, sino que quiero resaltar momentos (y no de manera excluyente) que considero deben ser tenidos en cuenta para seguir el recorrido por el cual llegará a América Latina, el discurso más influyente sobre la unidad del Derecho procesal.

* Doutor em Direito pela Università degli Studi di Macerata - Itália 


\section{ELEMENTOS IMPORTANTES DENTRO DE LA CONSTRUCCIÓN DE UNA CIENCIA DEL DERECHO PROCESAL ESPAÑOL}

La historia del Derecho procesal científico para los países de habla hispana, tiene como referente indiscutible la figura de Niceto Alcalá-Zamora y Castillo. El nombre del catedrático de Santiago de Compostela, saldrá a relucir en cualquiera de las recientes invocaciones a la temática.

Fue precisamente en el concurso para la obtención de la plaza como profesor en la Universidad de Santiago de Compostela, donde por vez primera aparece una exposición detallada sobre una teoría general unitaria del Derecho procesal en lengua castellana.

Pero esta exposición del profesor no es obra de la improvisación o de una invención toda de Niceto. Antes de llegar la propuesta que hace Niceto Alcalá-Zamora y Castillo en las oposiciones a la cátedra de Derecho procesal de la Universidad de Santiago de Compostela, debemos tener en cuenta que diversos factores que resultarán decisivos en la conformación cultural, ideológica y jurídica de esta figura, modelarán sin duda la exposición que he señalado. He dividido en diferentes momentos esta formación, para dibujar una idea incompleta, pero necesaria, de estas distintas circunstancias.

\subsection{La tradición unitaria en la enseñanza del derecho procesal en España}

El hecho de ser España la última gran potencia política medieval condicionó la manera en la que se organizaron muchas de sus instituciones sociales e incluso, la manera en la que se desarrolló cierta identidad cultural, que sin lugar a dudas tendría alguna repercusión en el espacio de lo jurídico. Numerosas de las peculiares características del pasaje del antiguo régimen a la contemporaneidad en España se debieron a esta singular circunstancia de haber logrado construir el más estable proyecto político de raigambre o inspiración feudal, para una época en la que este ya estaba en franca y absoluta descomposición. ${ }^{1}$

El desarrollo del Derecho en una sociedad, como fenómeno cultural, está sometido a muchos y distintos factores. En este caso nos interesa hacer referencia al peso que tendrá para el desarrollo del Derecho procesal, la evolución de la enseñanza del Derecho de esta materia en las universidades españolas. Pues como veremos con posterioridad, esta cuestión tendrá relevante importancia en el desarrollo de una teoría general unitaria del Derecho procesal. ${ }^{2}$

Desde el siglo XVIII el atraso de los estudios jurídicos en las universidades españolas era notado, incluso entre los mismos españoles. Por todos lados en la cultura española se hablaba de crisis, y el Derecho como existencia propia de la cultura de la sociedad, no quedaba al margen de la crítica. Si bien hasta hacía poco 
más de un siglo, esta "crisis" al parecer no era una cuestión que interesara a un amplio sector de las capas cultas de la sociedad, e incluso, todavía la experiencia de la universidad de Salamanca, era tomada como el ejemplo orgulloso de una España imperial que triunfaba no solo en la conquista y cristianización de un continente, sino en la producción de saber. ${ }^{3}$ Lo cierto es que con el auge de las ideas capitalistas y con el relego paulatino de la sociedad de súbditos, comenzó a declinar de manera acelerada la importancia de la producción doctrinal española. Así el ilustre Gaspar Melchor ya habría de señalar en una muy famosa carta al doctor Prado de la Universidad de Oviedo que “...no puedo dejar de aplaudir el celo con que se declara... en contra el dañoso método de la enseñanza del derecho que de tan antiguo siguen, y que todavía protegen nuestras universidades."

No sería un error si consideramos la experiencia salmantina como referencia de la enseñanza del Derecho español del Antiguo régimen, por ser durante la experiencia medieval española el centro de estudios universitarios que sirvió a la reproducción y fortalecimiento de la Monarquía. El plan de estudios de la Universidad de Salamanca, significó la base de la formación unificada de los estudios de Derecho con posterioridad para los planes que se desarrollarán en la actualización liberal. ${ }^{5}$ Veamos entonces algunas características de la enseñanza del Derecho de la universidad salmantina.

La enseñanza del Derecho del antiguo régimen español tuvo como elemento característico, que los estudios se orientaron a la solución de problemas jurídicos puntuales llevados para ser discutidos como casos prácticos por los maestros. Esto quiere decir que en las aulas universitarias los estudiantes fundamentalmente aprendían a localizar y combinar el Derecho de acuerdo al valor atribuido a los distintos elementos constitutivos: doctrinal, religioso, real, corporativo, consuetudinario, que condujera a la solución del conflicto. Para lograr una solución en este sentido, debemos tener en cuenta que en el amasijo normativo del antiguo régimen español, subyacía el concepto de unidad y complementariedad (no contradictoria) de los distintos derechos, estableciéndose una referencia preferible en el iuscommune. ${ }^{6}$ Por lo tanto, en este período prevalecía una indefinición sobre la enseñanza misma del Derecho procesal, que sólo incidentalmente aparece en el Derecho que se estudia en las universidades.

En el proceso por el cual se extiende por Europa lo que conocemos como Modernidad, las estructuras políticas tienden a una centralización (y centralidad) que transforman el entorno cultural en sentido general, reforzándose el poder político estatal como un ente importante en la construcción de imaginarios culturales. $^{7}$

Para el Derecho español, esta cuestión será muy visible con los reyes ilustrados, los cuales verticalizarían la enseñanza a través de planes en los que se introducen los manuales para la enseñanza, con gran repercusión en la Licenciatura en Derecho. Estos manuales, que para el estudio de lo que conocemos hoy como Derecho procesal, seguían los modelos procedimentales que existían hasta 
entonces, no van a variar de manera sustancial la idea del proceso, como modo de comportamiento ante los tribunales. En esencia existió una continuidad de aquella indefinición procedimental germánica en la que no resulta trascendente la diferencia entre proceso civil o penal. ${ }^{8}$ Es por eso que en el cuerpo de textos para la educación en una materia que comenzaría a nacer de manera gradual, no puede haber distinción entre distintos procesos que en la práctica son esencialmente vistos como parte del mismo fenómeno de comparecer o presentarse ante el tribunal. ${ }^{9}$

No obstante esto, en el más concentrado poder del soberano, o digamos, en una soberanía concentrada en un poder con un más estrecho vínculo con el espacio público, está la esencia de la transformación gradual de aquella manera de entender el proceso como mero comportamiento ante el tribunal, para comenzar a pensar en problemas de distinta envergadura, como el tema de la justicia procesal. Será la influencia de la codificación y el desarrollo de la exegética la cual progresivamente introducirá un especializado Derecho procesal. Mientras tanto, el Derecho procesal estaría constituido esencialmente por costumbres, prácticas forenses, y muy poco reglado o estructurado de manera sistemática en el entramado legal. ${ }^{10}$

Pero la no existencia de un buen código sobre el cual desarrollar los estudios exegéticos y al mismo tiempo, la contradicción ideológica con la propuesta francesa, es la que seguramente permitirá una mirada más atenta a los estudios alemanes desde mediado del siglo XIX, la cual al menos ideológicamente no resulta tan subversiva como la experiencia francesa. Al finalizar este siglo, de cualquier manera, la enseñanza del Derecho procesal no se subordina a los estudios eminentemente separados en distintos derechos procesales que impone la exegética francesa, muy seguramente en la voluntad política de la supervivencia de un Derecho nacional, que no sede a las divisiones creadas por una potencia extranjera enemiga.

Un vistazo al nombre que en los sucesivos planes de estudios se le da a las asignaturas que evolucionarán hacia el Derecho procesal nos sirve para darnos cuenta de esta afirmación: planes ilustrados y revolucionarios 1821 y 1836: Práctica forense. Primeros planes liberales 1842-1852: Oratoria forense, teoría y práctica forense y Práctica forense, 1857-1880: Procedimientos, Oratoria forense, Práctica forense, Procedimiento y práctica forense; Segundos Planes Liberales, 1883-1900: Derecho administrativo, político y contencioso, Derecho penal y procedimiento, Derecho procesal, Redacción de instrumentos públicos y judiciales, Derecho procesal y redacción, 1921-1953: Derecho procesal $^{11}$.

Aún con algunas excepciones de corto alcance, la materia procesal en España, desde la irrupción de la enseñanza liberal, estuvo marcada por la unidad de la misma.

Cuando en 1932 Niceto Alcalá-Zamora y Castillo habla por vez primera de una teoría unitaria para el Derecho procesal en lengua castellana en su escrito 
para las oposiciones a la cátedra de Derecho procesal de la Universidad de Santiago de Compostela, la enseñanza del Derecho en la universidad española tenía ya una larga experiencia en una concepción unificada de la materia.

\subsection{Factores políticos en la unidad del Derecho Procesal}

El Derecho no se puede sustraer de la política. Los dos fenómenos existen entrelazados íntimamente aun cuando en determinados momentos los vericuetos por los cuales se manifiesta esta relación parecen llevarlos por diversos cursos.

Así pues, la política española que desde inicios del siglo XIX sufre violentas transformaciones en el tortuoso pasaje de época ${ }^{12}$ y a pesar de un confuso escenario donde las tendencias y los colores políticos se entrecruzan, confunden y oponen, la unidad española será un tema común en los discursos políticos que a nivel nacional se proyectan hacia una España liberal deseada ${ }^{13}$. La pretensión de universalidad que conllevan los discursos culturales que alcanzan envergadura política, acuden al tema de la unidad de manera recurrente en la intención de ampliar el marco de desarrollo o de influencia, de reconocimiento de realidades que dejan de ser extrañas. Esta característica que en el proyecto cultural moderno, se encuentra raigalmente entronizada, se expresa con inusitada tensión de manera tardía en España con respecto a otras naciones europeas, siendo las Guerras Carlistas expresión de esta misma tirantez. Es por ello que a partir del siglo XIX, la unidad española forma parte íntima del discurso unitario político español, y parte de la pretensión de una España moderna. La unidad española se consolida con el plan moderno del Estado nacional, pero con raíces claras en el mismo feudalismo cada vez más centralizador que se pierde en el tiempo entre historia y leyendas. Este hecho, como dato de interés, representa el compromiso del rey de ser soberano de distintos reinos, o sea: la corona como realidad política que unió espacios, pueblos y culturas que podían ser relativamente diferentes, o sensiblemente dispares. Esta unidad de España, fue entonces, antes que nada, una unidad política que se expresó en el Derecho creando riqueza y tensión.

La implicación de esta construcción política para el Derecho incidirá de manera drástica en la cuestión de las fuentes del Derecho: numerosas y confusas. Fue reconocido que el arsenal normativo del reino español resultaban materialmente inmanejables, aun cuando el ejercicio real del Derecho no representase el manejo absoluto de estos cuerpos legales. Para tener una idea del estado de cosas en 1836, podemos acudir al profesor Domingo Porras Quiroga de la Universidad de Santiago, quien señala que ese momento permanecían vigentes la friolera cifra de 13527 normas (con su respectivo y a menudo numeroso articulado), según cálculo por él mismo realizado y distribuidas de la siguiente manera: Fuero Juzgo 576 leyes; Fuero Viejo de Castilla 474 leyes; Fuero Real y Leyes del Estilo 789 leyes; Ordenamiento Real de Alcalá 124 leyes; Partidas 2752 
leyes; Novísima Recopilación 3600 leyes; Decretos del Sr. Don Fernando $7^{\circ}$ y S.M. La Reina Gobernadora 5212 leyes. ${ }^{14}$

El discurso de la unidad jurídica española se hará fuerte sobre todo a partir de la segunda mitad del siglo XIX, cuando inevitablemente el complejo entramado jurídico medieval, entra en la más clara crisis ante la implementación de un centralizado ejercicio del poder político y el desarrollo de una administración española cada vez más ajustada a los tiempos. La experiencia codificadora europea (y sus ecos en España), la necesidad de un aparato administrativo más eficiente, y el desarrollo de la industria y el comercio, son las causas de un llamado, cada vez más urgente, a dicha unidad. A pesar de que el Derecho penal, público y mercantil llegan a ser parte de la proyección jurídica de los gobernantes liberales españoles, el Derecho civil foral, las instituciones de siempre, resultaban inamovibles y todavía a inicios del siglo XX esta unidad aparece como un deseo de materialización escurridiza. ${ }^{15}$

Pero en 1924 España se encuentra viviendo un momento de florecimiento de los estudios de todo tipo, donde se desarrollan proyectos culturales de importante repercusión ${ }^{16}$ para la posterior configuración de la España actual. El contexto cultural es de por sí propicio a reflexiones jurídico-políticas que logran imbricar el discurso de lo nacional como fenómeno inclusivo, que no resulta hermético a la recepción y el intercambio de distintas tradiciones y extracciones culturales ${ }^{17}$. Es en este contexto en el que el padre de la figura que estudiamos, el señor Niceto Alcalá-Zamora y Torres, quien seis años después asumiría la presidencia de la Segunda República Española, publica un memorable ensayo de tema La unidad del Estado y la diversidad de sus legislaciones civiles ${ }^{18}$.

En este artículo está presente una suerte de exposición programática de Niceto (padre) respecto a su percepción de lo político y lo jurídico. El tema no es tratado por Niceto (padre) por vez primera, pues ya con anterioridad había pronunciado importantes discursos y publicado artículos donde trataba el tema ${ }^{19}$ ya sea de manera central o como parte de su proyección política general, pero nunca como en esta ocasión brindando el espacio esencial al fenómeno jurídico. Para la fecha en la que aparece el artículo en cuestión, Niceto Alcalcá-Zamora y Castillo, estudia Derecho en la Universidad Central y no puede ser ajeno ni a la política, ni a las ideas sobre la unificación del Derecho, pues, como veremos luego, desde la misma academia, el tema está siendo observado por un importante sector de la doctrina más activa española.

\subsection{Influencia francesa}

Los fenómenos culturales son humanamente complejos, y por lo tanto, podrían perfectamente ser tan infinitos como humanos lo estudian o viven. No ubico la repercusión de los acontecimientos franceses en este lugar por orden de importancia sino sólo por la manera en la que he engranado los argumentos. Que 
Francia resulte un referente cultural en el espacio europeo de finales de siglo XVIII y durante el siglo XIX resulta una cuestión innegable. Voltaire, la Enciclopedia, La Revolución, Napoleón y su Code, fueron símbolos que recorrieron los confines europeos avisando que la época de los reyes, tal y como había sido contada hasta entonces, comenzaba a llegar a su fin. A nosotros nos interesa de manera particular por la importancia que tiene en el desarrollo del pensamiento y la cultura jurídica, el Código Napoleónico, pues el alcance del fenómeno de la codificación transformó el Derecho de su tiempo y modeló el Derecho y la cultura jurídica que le sucedió. ${ }^{20}$

Para el Derecho procesal resulta de gran importancia la contraposición que existió entre la idea de la codificación (que en el imaginario español se dibujará extranjerizante, atea y anticlerical) y una tradición jurídica basada en el Derecho común y foral, que sería reconocido como elemento de la identidad jurídica española. Debemos tener en cuenta que el Derecho resulta generalmente una estructura social de lenta transformación donde raramente ocurren bruscas fracturas con el pasado, (ni siquiera en las revoluciones esta fractura es tan radical como para no reconocer el Derecho de antes de la revolución) por lo que no resultará raro que ante el empuje de nuevas ideas, exista una poderosa oposición a las transformaciones del status quo ${ }^{21}$. La recepción de la codificación es gradual (y escabrosa) por el profundo e indiscutible significado político que el código lleva consigo. Muchos sabían que la idea misma del Código vendría a subvertir el orden jurídico existente. La cultura jurídica española se había compenetrado íntimamente con el pensamiento aristotélico medieval en el cual atacar alguno de sus componentes, representaba a su vez un ataque al todo (holismo aristotélico). ${ }^{22}$

La idea del código como enemigo del orden establecido, como herética propuesta a la tradición católica del pueblo español, la veremos expresada por ejemplo en la censura a "La Décadephilosophique, littéraire et politique" donde aparecen publicado y comentado el Código Napoleónico y que había querido ser vertida al castellano por José Meneses Montemayor en $1802 .{ }^{23}$ Sin embargo, el código tiene otra manera de llegar al pensamiento jurídico español y será sobre todo a partir del ejercicio de la exégesis.

El auge de los estudios de Derecho vinculados al estudio de la norma, será fundamental para el desarrollo de la cultura jurídica. Como sabemos, el volumen de producción doctrinal alrededor de los códigos mismos será sensiblemente mayor a la producción jurídica que hasta aquel momento se había desarrollado. ${ }^{24}$ Para España será fundamental en ese sentido, el desarrollo de la Casación, otra institución que aunque de raíz francesa, evoluciona particularmente en territorio español y seguramente sirve para que de manera indirecta, el ideal codificador vaya consolidándose. $^{25}$

La institución de la casación es generalmente asociada a la revolución francesa, como mecanismo de control del órgano legislativo para garantizar que la ley no se transforme por la interpretación de los jueces. La casación de esta forma es entendida como un instrumento político para el control de la voluntad expresada por el legislador, como un instrumento nomofiláctico. 
Sin embargo, la casación no es una propuesta totalmente nueva de la Revolución Francesa, sino que encuentra sus antecedentes en una Ordenanza de 23 de marzo de $1302^{26}$ para la creación de un órgano de control que desde el Poder central controlase el cumplimiento de la ley por parte de los distintos Parlamentos, que comienzan a desarrollarse desde el mismo 1302, pero que toman fuerza a partir de 1315 en el reinado de Luis $\mathrm{X}^{27}$ ). Es por esa raigambre feudal por la cual no será vista de manera peligrosa una casación española. A diferencia de la casación francesa que será entendida como norma revolucionaria para el control de los jueces, la casación española será un instrumento jurisdiccional para la doctrina española para tender un hilo de Ariadna entre los vericuetos de la muy (demasiado) prolífica legislación española.

El primer antecedente sobre un recurso de este tipo lo hallamos en la Constitución política de $1812^{28}$ con el recurso de nulidad. Más tarde evolucionarála nulidad hacia una casación peculiar que se introduce tanto por el afrancesamiento de la cultura en general, como por la necesidad de dar cierta estructura al sistema de recursos que "se había transformado en algo extremadamente complejo ${ }^{29 "}$ "Estos recursos son los mismos que hasta ahora se han denominado entre nosotros como recursos de nulidad: en la nueva Ley se ha sustituido a esta palabra la de casación, sin duda por considerarla más concreta y técnica, y por ser de uso general en el foro de toda Europa. ${ }^{30}$

Código y Casación serán parte del desarrollo de una cultura jurídica de la burguesía que transmite un compromiso de estructurar una unidad jurisdiccional necesaria en la transformación funcional en los gobiernos modernos "de los países civilizados". La casación servirá para "hacer comprender á los jurisconsultos la importancia y trascendencia... en pro de la claridad y fijeza de nuestra varia, confusa y á veces contradictoria juriprudencia" ${ }^{31}$. Que los jueces resultaran ser los comentaristas mas relevantes a partir de la introducción de la nulidad de 1812 resulta descriptivo del papel de los mismos en la consolidación de la doctrina en función de la organicidad legal española ${ }^{32}$ y el desarrollo de una cultura jurídica que sucesivamente tenderá a una estructuración sistemática: "La casación española sin códigos se presenta, en primer lugar, como el terreno de la lucha por la definición y alcance de los inaprensibles Códigos españoles..." ${ }^{33}$. Mientras tanto los enardecimientos primeros que produjeron los intentos de introducción del código se han ido calmando y evolucionando de manera distinta a las primeras rotundas oposiciones.

La casación será el elemento que intentará producir una ciencia de la exégesis sin código, que si bien algo hizo por una conciencia hacia la unidad del Derecho, poco logró en términos de sistematicidad dogmática.

Los krausistas intentarían, por su parte, llevar el Derecho al plano de la filosofía como piedra de toque filosofal sobre la naturaleza de lo humano. Este transcendentalismo español, no es más que una permuta con Dios. En otras palabras, todo aquello que representa una cultura jurídica de la descripción, del regodeo en la grandeza de la razón del legislador. 
Este recorrido que hemos visto establece una relación entre código y casación en la conformación de un pensamiento jurídico tendiente a un sistema jurídico más articulado. Sin embargo, el reajuste en el plano iusfilosófico viene operándose con el desarrollo del krausismo español. Para ese entonces el código ya ha adquirido una fuerza de utopía jurídica, orientado a la unidad y la sistemática.

\subsection{El krausismo}

El krausismo es un fenómeno largamente estudiado por el alcance que ha tenido para toda la cultura española desde que emergió como movimiento de élites culturales hasta un asentamiento institucionalizado, sobre todo a finales del siglo XIX e inicios del siglo XX. Como corriente filosófica se desarrolla con fuerza casi exclusivamente en territorio ibérico y debe su introducción en España por la necesidad de un soporte filosófico para la transformador del status quo anquilosado en un conservadurismo dañino a la sociedad española en sentido general. El basamento teórico de esta corriente se encuentra en la obra de Karl Christian Friedrich Krause, quien recrea un sistema mediante el cual se puede explicar la relación del hombre con Dios a través de la absorción en Dios, de la naturaleza, el espíritu y la humanidad. La historia según Krause en un viaje al regreso a Dios, el cual es el fin de todo el progreso. Ni en Alemania, ni en ninguno de los países que visitó (por aquello de que nadie es profeta en su tierra), tuvo una acogida consistente, sin embargo, tuvo algunos importantes discípulos que divulgaron sus ideas en universidades europeas. ${ }^{34}$

Uno de estos discípulos, Heinrich Ahrens publicó en 1838 un Cours de Droitnaturelou de philosophie du Droit, que tuvo muy buena acogida con tres ediciones consecutivas en París, una en Bélgica, y otra en Austria. En 1841 este libro fue traducido por Ruperto Navarro Zamorano y prontamente fue incluido como texto de enseñanza en algunas universidades españolas y durante ese mismo curso escolar, fue también condenado por la Iglesia Católica. Señala GonzáloCapellan de Miguel, profesor de la Universidad de Cantabria:

La apuntada naturaleza de su pensamiento así como su progresiva aceptación, que comenzaba a revertir cierta importancia, fue la responsable de que enseguida los sectores más radicales del conservadurismo español sintieran esa amenaza y reaccionaran inmediatamente tratando de despretigiar al krausismo. Los sectores más integristas del tradicionalismo fueron los principales encargados de llevar a cabo esa crítica. Ello era lógico si tenemos en cuenta que al krausismo se le identificaba en el plano político con el liberalismo (condenado en el Syllabus del Pío IX), considerándolo responsable directo de la revolución de 1868; y en el religioso con el anticatolicismo; y en el plano social con la secularización de la enseñanza, que socavaba de forma manifiesta los resortes fundamentales del poder de la Iglesia. ${ }^{35}$ 
La reacción conservadora no dejó de hacer notar su desacuerdo con la obra que se había traducido al castellano. En 1945 en la revista La Censura, apareció una reseña de la traducción del libro de Ahrens en dos páginas donde señalaban que

Así advertimos a los padres de familia que si quieren cumplir con un deber sagrado de conciencia, y no ser responsables de la perdición de sus hijos, están obligados a prohibir a estos la lectura y manejo de la obra en cuestión, como también la asistencia a las aulas donde se explica por texto. ${ }^{36}$

No obstante esto, un discípulo y amigo de Ruperto Navarro Zamorano, Julían Sanz de Rio, se apresuró a visitar a Ahrens en Bruselas, y a partir de allí madura definitivamente la idea de promover una filosofía que sirviese de base a una teoría política y de transformación social en España. El obtener Sanz del Rio, la cátedra de Filosofía del Derecho de la Universidad Central de Madrid, fue útil para la formación de una generación que estudió la filosofía del Derecho basada en los ideales que defendía Sanz del Rio.

El proyecto de este autor logra acoger un número importante e ilustre de seguidores, sobre todo a partir de la traducción de Ideal de la Humanidad para la Vida. Este grupo asume el krausismo en diferentes esferas de la actividad social, por lo que el proyecto krausista fue además que una propuesta filosófica, un proyecto pedagógico que recogió prolíficos frutos. Es el contenido pedagógico el que permitirá la difusión del krausismo como instrumento de transformación cultural. Signos de la pronta vinculación con importante figuras políticas que influyeron de manera positiva en la difusión de los ideales krausistas los encontramos, por ejemplo, desde la primera edición de la traducción por Julían del Rio, cuando en su dedicatoria el traductor usa sentidas palabras de agradecimiento al Ministro de gobernación Pedro Gómez de la Serna. La articulación del krausismo en la cultura española, representará la definitiva recepción del pensamiento liberal, soportado ahora por una filosofía que corresponde con la necesidad española. Un resultado importante de esta recepción es la posibilidad de encontrar un soporte a la transformación epistemológica necesaria a las ciencias españolas.

Desde el siglo pasado, se habían ya dado importantes pasos en el sentido de una búsqueda de aproximación de la cultura española a la iluminación moderna, aunque en realidad, la excepcionalidad de la figura de Gaspar Melchor de Jovellanos, no logró el estremecimiento que necesitaban los espacios académicos y científicos. Es precisamente Jovellanos, quien había presentado el problema de la ciencia del Derecho desde la citada carta Sobre el método de estudiar el Derecho, cuando al hacer referencia al estudio del mismo halla su cientificidad porque es "una colección de ideas clara y distintamente concebidas y ordenadas 
en nuestro espíritu acerca de un objeto" con una "clara y distinta percepción, comparación y disposición de las ideas". ${ }^{37}$ Aunque el pensamiento de Jovellanos es coherente con el desarrollo del ideal liberal y el humanismo ilustrado, no sirvió a la transformación que si necesita España: un viraje en la manera de entender, estudiar y transformar el mundo.

Con el krausismo este instrumento si llega, y llega además desde el Derecho mismo, a través del estudio de la obra de Ahrens sobre el Derecho natural. A través de la nueva propuesta se podrá releer el desarrollo de la codificación de manera más relajada que con anterioridad. Es por ello que la recepción de la codificación en España opera a partir de dirigir la mirada, no hacia la Francia modernizadora, sino sobre todo a partir de la introducción de la cultura alemana a través del krausismo.

El historicismo alemán fue el que brindó el instrumental para la construcción del sistema de Derecho en España. En la península ibérica no bastaba una propuesta sólida como el código, pues la tradición del Derecho Foral y Común vivían de una fortísima tradición, que todavía en la Novísima Recopilación de 1806 daba a un ejército de operadores del Derecho el material para considerar con vitalidad un Derecho a todas luces caduco. Este ejército todavía a mediados de siglo será un lastre para transformaciones de envergadura.

De inspiración krausista fue la creación de la Institución de Libre Enseñanza en 1876, por lo cual a muchos krausistas se les comienza a conocer como "institucionistas". Este hecho tuvo una repercusión tremenda en cuanto nace de la voluntad de un grupo de docentes de defender la libertad de cátedra, contra el modelo canovista ${ }^{38}$, por lo cual son separados de la enseñanza universitaria. Entre los integrantes del grupo de profesores se destacan: Francisco Giner de los Ríos, Gumersindo de Azcárate, Teodoro Sainz Rueda, Nicolás Salmerón, Joaquín Costa, Augusto González de Linares, Hermenegildo Giner y Federico Rubio, entre otros.

Es precisamente en esta experiencia jurídica con base en el desarrollo del krausismo, en la que se consolida una visión del sistema de Derecho de procedencia alemana. Las élites culturales jurídicas pertenecientes a estas experiencias renovadoras estudiarán con atención estas ideas de sistema no ya en un sentido eolístico quizás como la tradición aristotélica, sino en un sentido moderno ${ }^{39}$. La traducción del Sistema del Derecho Romano Actual de Savigny, pasa del Alemán al Francés a través de M. CH. Guenoux, para llegar al castellano con los Profesores de Derecho Romano en la Institución Libre de Enseñanza, Jacinto Mesía y Manuel Poley. ${ }^{40}$ La introducción de la traducción española de Manuel Durán y Bas resulta así mismo un espejo de preocupaciones que no podemos dejar escapar en este espacio. 
Exponer el Derecho romano actual, no como tratado, sino como sistema, es conquistar en el terreno científico carta de naturaleza para un principio no siempre comprendido, y sobre todo nunca doctrinalmente formulado por los antiguos: el de que el derecho privado positivo desenvuelve un organismo natural, que toma forma histórica en las diversas legislaciones civiles. Así considerada esta rama del derecho preséntanse sus partes como instituciones que tienen también organismo propio, pero dotadas de aptitud para tomar color local y armonizar lo que es de su esencia con lo que caracteriza la civilización de cada pueblo. ${ }^{41}$

El tratamiento del Derecho será entendido entre los krausistas a nivel de sistema, no como referencia a intrincadas estructuras de Derecho, sino a un Derecho que es sistema en cuanto se conforma a partir de principios sobre los que evoluciona una dogmática ius-privatística, base de la ciencia nueva. Esto es visto como la posibilidad de relacionar el elemento histórico con el racional, pues "Ahrens señala como uno de los principales méritos de la doctrina de Krause el que es la que mejor combina la alianza de la filosofía con la historia; la unión íntima del elemento histórico con el elemento racional".42

Esta amalgama permitirá una relación entre la exégesis y la dogmática civilística que potencia la labor doctrinal que desde la casación se realiza.

Para inicios del siglo XX, el krausismo, la Institución de Libre Enseñanza y los proyectos relacionados eran parte esencial de la vida cultural española, vinculada a diferentes círculos políticos y a la vida académica misma. Se creó el Museo Pedagógico Nacional, el Boletín de la Institución de Libre Enseñanza, el Centro de Estudios Históricos, la Residencia de Estudiantes y la Junta para la Ampliación de Estudios, esta última planeada para otorgar becas en universidades extranjeras a los estudiosos españoles. Todas estas experiencias tuvieron un impacto decisivo en el desarrollo de la cultura jurídica española de inicios del siglo XX. Una cosa quedó clara en este proceso: poco a poco la cultura jurídica alemana se convertiría en un referente que será estudiando con más atención ${ }^{43}$.

Para el posterior desarrollo del Derecho procesal se da una cuestión interesante: Por una parte, la experiencia codificadora francesa, había hecho una radical escisión entre un proceso civil, atado al código de Derecho civil y otro penal, atado al código penal. Por otro lado, en la experiencia alemana, el desarrollo de los estudios de la dogmática jurídica, favorecerá los estudios de Derecho civil, a partir de los cuales se irradia una ciencia del Derecho fundamentalmente civilística que tendrá como resultado un estudio del fenómeno procesal a partir de categorías de esa rama del Derecho. ${ }^{44}$

Entonces, la unidad del Derecho procesal parecería romperse en la recepción del Derecho extranjero, si no fuera por los dos elementos analizados con anterioridad: la educación en un sentido unionista para el Derecho Procesal y la voluntad de algunos políticos en la unidad del Derecho español. Sin embargo, 
el mismo factor que provocaría la fractura del proceso, en su concepción feudal, también brindaría las herramientas para su re-elaboración, lanzándolo a una nueva dimensión: la de ciencia jurídica.

En la promoción del pensamiento procesalista nuevo en España, diferente tanto a la tradición de raigambre feudal como a aquella de la exégesis, todos los personajes que aparecerán ligados a la promoción del Derecho procesal durante la década del 20 e inicios de la década del 30 español, están involucrados de manera cierta y comprometida con el krausismo. Algunos de estos nombres mantienen una trabazón directa entre desarrollo del procesalismo, y la manifestación krausista mas visible de la época, los institucionistas, así tenemos a Xiaru y Beceña, considerados unánimemente pioneros del procesalismo español.

Otros vínculos de los krausistas con el desarrollo del Derecho procesal no son tan evidentes pues establecen la relación indirectamente, pues inciden en el desarrollo del Derecho procesal; no en la construcción directa del entramado conceptual o doctrinal, sino que forma parte de la conformación del entorno institucional necesario para la aparición, consolidación y finalmente elaboración doctrinal del Derecho procesal. Así por ejemplo José Castillejo no puede ser obviado de ninguna historia de las ciencias españolas, (cuestión que toma cierta relevancia al comprobar que este eminente personaje fuese jurista y pedagogo) o como veremos luego, figuras más estrechamente vinculadas a la producción jurídico-doctrinal, pero no relacionadas directamente con el Derecho Procesal aunque tendrán un peso en el desarrollo posterior del mismo como Luis Jiménez de Asúa.

\subsection{Irrupción del Derecho procesal científico en España}

La ilustración lo quiere convertir todo en ciencia, todo el saber humano es susceptible de ser una ciencia, toda reunión de conocimiento podría potencialmente ser una ciencia, y así se hablará del conocimiento como ciencia. La referencia que hicimos con anterioridad a Jovellanos ${ }^{45}$ nos trasmitía la concepción del Derecho como ciencia, pero en un sentido muy dilatado. Poco a poco, esta pretensión de la ciencia como conocimiento, se amolda a un más preciso espacio de reflexión, marcado por el establecimiento de métodos analíticos más sofisticados.

En el Derecho será ciencia aquel saber, en cuanto más que amalgamarse y superponerse, se comience a sistematizar. Esta misma sistematización, ocurre con mucha mayor energía a partir del desarrollo de la exégesis francesa y el Derecho de conceptos de la escuela histórica alemana. Una nota distintiva diferenciadora entre estos dos proyectos culturales es, que la doctrina que emerge del código en el caso francés, estará mucho más subordinada a una posición contemplativa respecto al objeto de estudio, mientras que la metodología alemana permitirá un estudio de profundidad mayor. 
La "ciencia" del Derecho procesal, llegará a España en un recorrido que tendrá como principal referente la producción doctrinal italiana, y no precisamente a partir de la obra de Chiovenda. Antes de la época de primacía absoluta de la escuela del profesor de Roma, nos podemos percatar que existe ya un acercamiento a la doctrina italiana de parte de los autores españoles.

En la Revista General de Legislación y Jurisprudencia, Carlos Lessona desde el año 1895 da a conocer al público de la revista los trabajos "Génesis histórica del art. 737 del Código Civil Español", "La institución de los hombres buenos" (1896), "El duelo en los nuevos estudios y en las nuevas ideas" (1896) y "Los deberes sociales del Derecho procesal civil" (1897-1898). En 1898 aparecía la traducción al castellano de la "Teoría General de la prueba en derecho civil", de la mano de Enrique Aguilera de Paz y con una introducción de José María Manresa y Navarro, quien además había sido figura clave en la redacción de la Ley de Enjuiciamiento Civil de $1881^{46}$ y director de la misma Revista General de Legislación y Jurisprudencia.

Más adelante en 1914, José María Fábregas del Pilar reseña el primer libro de Calamandrei: "La chiamata in garantia: studioteorico-pratico di dirittoprocessualecivile" (1913), donde además se da cuenta del crecimiento de los estudios de Derecho procesal en la península itálica. Lessona, el procesalista italiano más conocido ha pasado la batuta del derecho procesal a Calamandrei: en el artículo que señalé de Fábregas este señala que "El eminente profesor Carlos Lessona, cuyas obras son tan conocidas y apreciadas por los juristas españoles, abrió la era de esta renovación del derecho procesal, y a sus meritísimos estudios han seguido practicados por sus discípulos, entre los cuales figura el autor de esta obra" ${ }^{37}$.

Incluso, antes de que el primado de Chiovenda en Italia y luego en todo el Derecho procesal, fuese un hecho consolidado, el catedrático Tomás Montejo y Rica ya lo había citado en el discurso leído el 27 de febrero de 1916 con motivo del ingreso del profesor Montejo en la Real Academia de Ciencias Morales y Políticas. El discurso que apareció publicado ese mismo año con el nombre de La función judicial hace especial referencia al célebre ensayo "Lazionenel sistema deidiritti". Pero, es a partir de los años 20 del siglo XX donde comienza a desarrollarse y definitivamente a consolidarse la relación entre los estudiosos de Derecho procesal españoles e italianos.

Sobre este período es indispensable acudir a los estudios del profesor Manuel Cachón, profesor de Derecho procesal por la Universidad de Barcelona, quien ha profundizado en el estudio de la historia del Derecho procesal en su patria a inicios del siglos XX, y que en la actualidad todavía se encuentra inmerso en interesantes proyectos. Necesariamente en los próximos párrafos no puedo sustraerme de estos estudios, de los que haré constante uso.

Sabemos que hay una historia del Derecho procesal, que se encuentra sólidamente afianzada entre profesores y prácticos, sobre el desarrollo del Derecho procesal científico a partir del ocaso de la exegética del siglo XIX. Esta 
historia tiene como héroe, a Giusseppe Chiovenda que parecería emerger de las tinieblas ${ }^{48}$ y propone una revolución para el Derecho procesal a partir de los principios de oralidad, concentración e inmediación. En esta historia, de la cual además el mismo Niceto Alcalá-Zamora y Castillo ha contribuido a consolidar y difundir en idioma español y en todo el continente Americano, se reserva a Chiovenda el papel de maestro fundador del procesalismo científico italiano, mientras Calamandrei, Rendi, Liebman y ocasionalmente Carnelutti, se tratan como discípulos del "Sumo Chiovenda"."

No obstante, se habla también de una contra-historia que propone Cipriani en varios de sus estudios, sobre todo en Storie di processualisti e di oligarchi de 1991 e IlCodice di proceduraciviletragerarchi e processualisti de $1992 .{ }^{50}$ En este caso la historia que Cipriani propone, aparece mucho más cercana a la naturaleza humana misma, encontrándose con los nexos de intereses, pretensiones personales, glorias y miserias, por las cuales se consolida Chiovenda (en oposición a otras figuras como la fundamentalísima de Mortara,) como "padre" de la escuela italiana de Derecho procesal.

En esta contra-historia cuyo estudio nos lleva a la introducción del Derecho procesal en España veremos que a todas luces, Calamandrei parecería haber preparado una "operación historiográfica" para un lanzamiento por todo lo alto de una escuela italiana de Derecho procesal. Esta interpretación no pretende deslucir el fundamental papel de los procesalistas italianos, ni la centralidad y valía de la figura de Chiovenda, pero que será sin dudas potenciado a partir sobre todo de la obra del mismo Calamandrei.

Sabemos que al menos desde 1924 existen relaciones entre el profesor de Derecho procesal de la Universidad de Barcelona, Xirau y el de Firenze, Calamandrei. La relación entre ambos al parecer nace a partir de una carta que dirige el profesor Florentino al Barcelonés en agradecimiento de una reseña a La CazzioneCivile. En esta carta Calamandrei señala:

"Sonoveramentelieto di essereentrato in rapportipersonali con un collegaspagnolo che si interessa di argomentiprocessuali; e mi permetto di inviarLe a parte altrimieilavorigiuridici e di farle mandare in omaggio i priminumeridella 'Rivista di dirittoprocessualecivile', di cui sonoradattore capo. Avreimolto caro se noipotessimostabilire uno scambio di collaboraziones cientifica; per esempioiosareilietissimo di pubblicarenellamiaRivista un Suorendicontosullecondizioniattuali del processocivile in Spagna e sulleriformegiudiziarierecenti, imminenti o sperate" ${ }^{\text {"1 }}$.

Efectivamente en 1925 apareció en la Rivista di Diritto processuales civile, el artículo "Le condizioniattuali del processocivile in Ispagna" $52 \mathrm{Al}$ año siguiente apareció en Español, la traducción de “Troppiavvocatti” por Xiaru (que había sido publicada anteriormente en 1921). 
Para la aparición de la traducción de "La condannanellespezagiudiziali", ocurre un hecho singular, y es la aparición en la contraportada del libro, de un retrato de Chiovenda que no era público, ni lo fue hasta muchos años después. ${ }^{53}$ Es muy probable que este retrato fuese facilitado por el mismo Chiovenda, que el mismo Xirau hubo de conocer por mediación de Calamandrei en una visita a Siena.

Sabemos también que en 1928, Chiovenda en algún momento hizo solicitud formal para poder visitar España para impartir unas conferencias de Derecho procesal en la Universidad de Barcelona, y sabemos también que esta solicitud fue desestimada y las conferencias no se efectuaron. ${ }^{54}$

En 1932 Xirau emprende un proyecto pretencioso, con una Revista Jurídica en la Facultad de Derecho de su universidad que aunque de poca duración (solo llegó a existir hasta 1934), puso de relieve la voluntad de actualizar los estudios del Derecho en la península. En esta publicación aparecerán trabajos de Chiovenda e incluso de James Goldschidth que se encontraba también implicado en estudios de Derecho procesal junto a los jóvenes procesalistas Leonardo Prieto-Castro y Niceto Alcalá-Zamora y Castillo. El mismo Calamandrei, quien publicó "La condemna" en Catalán, en el primer número de esta revista pp. 5-19, apareciendo por lo tanto el artículo primero en Catalán que en Italiano, pues la obra será presentada en Italia algunos meses después en Studi in onere de Federico Cammeo. ${ }^{55}$

Con Xirau aparece para la historia del Derecho procesal en España una consideración propuesta por Calamandrei que será clave para la construcción de aquella historia ortodoxa del Derecho procesal italiano. El mismo Calamandrei señala que "quello che mancava prima di Giusseppe Chiovenda era il sistema ${ }^{56 "}$ y Xirau confirmará en la introducción de La condena en costas: "Lo que se debe a Chiovenda es la elaboración del sistema." ${ }^{57}$

\subsection{Debate italiano sobre la unidad del Derecho procesal con limitada repercusión en España}

Mientras la escuela italiana de Derecho procesal definitivamente ha extendido su marco de influencia mucho más allá de sus fronteras, al interno del nutriente entorno italiano, los debates doctrinales sobre la materia, mantienen un vigor que enriquecerá aún más las reflexiones sobre la ciencia del Derecho procesal.

Una cuestión tratada en el período y que será de sumo interés para la próxima evolución de la construcción de una teoría general del Derecho procesal, es el tema de si constituye el Derecho procesal una rama única del Derecho o son varias ramas que se ajustan a una principal con la que se vincula de manera directa. Dicho en otras palabras, la construcción de una ciencia del Derecho procesal dependería de una determinación de un valor particular otorgado como 
rama que posee todos aquellos elementos por los cuales el estudio del Derecho procesal podría ser reclamado como una ciencia particular.

En realidad esta cuestión tiene antecedentes que se remontan a una época anterior a esta que estudiamos, teniendo que ir a urgar en la gestación institucional de la unidad de Italia. En la obra del profesor MatteoPescatore vamos a ver un interesante paso en el sentido que nos interesa. Pescatore, involucrado de manera definitiva en el diseño institucional del país desde 1864 propone la obra "Sposizione compendiosa dellaproceduracivile e criminale", que no solo resultará la más "compendiosa" de su tiempo, sino que en este volumen se manifiesta una voluntad sistémica alrededor del fenómeno del proceso, que no corresponde con el entorno imperante entre los procesalistas que en la época publican. Esta voluntad sistematizadora hallará eco luego en un curso de Derecho procesal que el profesor imparte en Torino.

Sobre el empeño sistémico, Pescatore nos señala en otro libro "Lógica del Diritto", un recorrido que nos da la señal de una transformación sobre la construcción del sistema al interno del Derecho procesal. En un pasaje que nos dibuja la cuestión que se está analizando, Pescatore nos señala:

Chiedereallametafisica le prime nozionisull'organismomorale e giuridico, e con questenozionistudiareildiritto, non quale si concepirebbe con falsa astrazione in uno stato che non esiste e non puòesistere, maquale realmente governagliuomini e le Società: decomporreildirittone' suoielementiprimitivi, considerarnel'ufficio e il modo di azionenellevariesfere che essogoverna: e nellasferadella vita civiledistinguerel'elementogiuridicorazionale, l'elementogiuridico positivo, e il vero rapporto che unisce e contempera i duetermini: separare nellagiurisprudenza la scienzadall'arte, segnareil limite in cui la scienzafinisce e l'arteincomincia, stabilireil principio scientificoqual supremo regolatoredell'arte, e a questo fine costruire un sistema compiutocoiprincipii del giuscomune, ossiadellaragiongiuridicanaturale, in cui sia data a priori la soluzione di tutti i casi giuridici-talisonogl'intendimentidellalogica del diritto. ${ }^{58}$

Esta descomposición en principios generales, en abstracciones jurídicas que permiten racionalizar el sistema, viene (y así mismo nos lo recuerda a cada instante Pescatore,) no solo del pensamiento de Kant, sino de VictorCousin. Con ello se pretende otorgar cientificidad al Derecho a partir de su vinculación con la filosofía, pues resultaría la filosofía la única que podría otorgar categoría de ciencia al saber.

Pescatorequien conoce la obra de Savigny, no comparte su ideario y así nos dice: 
IncominciareloestudiodeldirittodaquellodeldirittoRomanocredosia un fatale errore. Bisogna prima conoscereil sistema, le forme, lo spirito, illinguagio del dirittonellostatoattuale: e con talicognizionirisalendo al diritto Romano, bisognaseguirnepazientementeilprocessologico, e ad ogni fase, e in ogni parte tradurre le forme, le idee, illinguagio romano nelle forme, nelle idee, illinguaggio romano nelle forme, nellinguaggiocorrispondenti del diritto moderno, raffrontandosecosì ad una ad una le istituzioni che si correspondono.

Luego con LuiggiMattirolo, sobre todo a partir de su Trattatato di DirittoGiudiziario, se logra un alejamiento aún mayor de aquella idea por la cual el Derecho procesal era arte y ciencia. Con Mattirolo la exegética logra imponerse en el paradigma de producción doctrinal, quedando esta obra como referente indiscutible de los estudios del Derecho vinculado a las actuaciones de los tribunales. La asimilación de la moda doctrinal francesa, permitirá que aquella institución de la acción identificada completamente con el derecho, se transformará en una "qualità inerente al diritto". ${ }^{59}$ Esto además permite la entrada del Derecho procesal desde la excegética campo de las ciencias jurídicas, por vía diferente a aquella acción rodeada de antecedentes históricos que se desarrolla en Alemania. Esta experiencia de concepción unionista en Italia, no parece tener un desarrollo que cuajase de manera definitiva en la literatura especializada, pues solo primaría el estudio de la leyes procesales que nacían distanciadas entre sí desde su misma promulgación. Quizás otra historia hubiese sido, si los códigos modelos de entonces hubiesen nacido con una vocación unionista.

La próxima propuesta que comprende una construcción unionista alrededor del Derecho procesal, emerge a partir de la idea de la unidad de la jurisdicción, con Mortara como su más importante defensor. Esta posición es sobre todo expuesta a partir de su obra Lo stato moderno e la giustizia pero definitivamente expuesto en su Commentario del Codice e delle Leggi di Procedura Civile. Al respecto nos recuerda el profesor MassimoMeccarelli que la obra de Mortara a pesar de la apariencia de corte práctico-descriptívo de comentario al código, se trata en realidad de un momento en el cual es formulada una teoría general del derecho y del sistema jurídico. La reflexión del profesor Meccarelli nos lleva a asumir como base de esta construcción sistemática el ordenamiento jurídico visto desde el problema constitucional de la justicia, y por lo tanto la necesidad de la afirmación de la unidad de la jurisdicción. ${ }^{60}$ En esta concepción la función jurisdiccional como centro del Derecho procesal, no se pondrá una distinción entre procesos distintos de manera esencial, pues la jurisdicción, la base de la impartición de justicia, es única.

Las condiciones para las reflexiones entre los procesalistas sobre la unidad o diversidad del Derecho procesal se están sentando con rapidez y en 1906, aparece publicada la prolusión Il diritto pubblico e il privato nel nostro attuale processo civile ${ }^{61}$ del profesor Luigi Ferrara. En este escrito se confirma 
el valor de Mortara en la consolidación de la naturaleza de Derecho público del proceso además de hacer evidente la recepción veloz de la procesalística alemana en Italia. Esta recepción no es nueva y ha ido calando poco a poco entre algunos de estos procesalistas, sobre todos aquellos cercanos a los estudios del Derecho romano, como el mismo Chiovenda. El gran debate sobre la unidad o diversidad del Derecho procesal (esencialmente entre el Derecho procesal civil y penal), comenzará apenas dos años después del artículo de Ferrara.

La chispa de esta experiencia prende cuando en la primera página de los Elementi di procedurapenale, el profesor Luigi Lucchini se ha apurado en señalar que "Al diritto penale, quindi, fa riscontro una procedura, nello stesso modo che una procedura fa riscontro al diritto civile" y para asegurar que "Nè, altronde, si posson dire per anco ben definiti i confini delle due scienze, che si contendono ancora la spettanza di uno o altro soggetto." 62 Pero es la propuesta de Agostino Diana, la que por primera vez presenta desnuda la situación de la unidad del Derecho procesal desde el mismo título de un ensayo, cual si proclama se tratase. Efectivamente tras "Lunità del processo e della dottrina processuale" de 1914, Diana se aventura contra los estudiosos de disciplinas procesales, diferentes a los cultores de la misma, desde una tradición civilística pues declara la superioridad de esta, para representar la guía de los estudios procesales. La tendencia a proclamar el Derecho procesal desde una óptica civilística como superior, se acrecienta, con el visto bueno de un ya reconocido Chiovenda, a un artículo de G. Battaglini de 1915 con título Dirittopenale y política criminale ${ }^{63}$. Que se apurasen los procesalistas que se dedicaban al Derecho procesal civil a reclamar un espacio preponderante no puede resultar extraño cuando en este mismo momento, se vive una crisis sobre la cientificidad del Derecho procesal civil. ${ }^{64}$

La clave del éxito de la propuesta unionista, está en la amalgama entre los presupuestos mortarianos más valiosos a la tradición científica del Derecho (aquella sistemática) y la doctrina chiovendana de rigor dogmático, considerando un transfondo liberal que soporta el intento de lograr una modernización italiana. La afirmación anterior incluso alcanza más valor cuando en el marco de esta experiencia sistematizadora, una violenta respuesta contestaria llegaría de Florian. ${ }^{65}$

Pues bien, el antecedente penalístico a la respuesta de Florian tendrá su base inmediata anterior en la obra de Ubaldo Pergola "L'istruttoria del processipenali." ${ }^{66}$ en la que reconocería una unidad de método pero que, el desmesurado uso de conceptos civilísticos al interno del proceso penal, produce "la artificiosa trasfigurazione" de conceptos civilísticos al límite de la absorción o la subordinación a aquella. Con las reflexiones de Pergola, nos damos cuenta que asistimos a la expresión de aquella penalística civil que el profesor Sbriccolillamaba la atención. ${ }^{67}$ Con aquel llamado de Diana, se acercaban peligrosamente los civilistas a pensar en el Derecho procesa penal, en un contexto en el que la scuola 
italiana de Derecho positivo, a pesar de su definitivo éxito, también comenzaba a ser criticada raigalmente, y la pandectística alemana se desarrollaba cada vez con más fortaleza.

Quizás se deba esta centralidad de la figura de Florianen este debate a la energía con la que desde Principi di dirittoprocessualepenale, se opone a la extraña invasión civilista, pues representaron sus palabras la más acusada oposición a dicha unidad. Todavía hoy Florian es invocado como el más feroz opositor a una teoría unitaria del Derecho procesal.

El sentido que marca esta discusión es la expresa voluntad y preocupación, de consolidar de manera científica el Derecho, que se logrará solo a través del tecnicismo jurídico.

\subsection{El camino hacia una teoría general unitaria del Derecho procesal en España, más allá de los procesalistas}

El procesalismo italiano, será esencialemente un procesalismo civilístico, y será luego civilística la recepción del mismo en España. Esta es esencialmente la idea que podemos hacernos de todos los estudios al respecto. Los más interesantes estudios sobre el tema los podemos buscar en los recorridos históricos que nos proponen los profesores Franco Cipriani, Juan Montero Aroca y Manuel Cachón.

El desarrollo de una teoría general unitaria del Derecho procesal, como ciencia no está muy claramente delimitado en la propuesta de sistematización que llega desde el tecnicismo de la dogmática civilística. En realidad esta cuestión no forma parte del las preocupaciones doctrinales de los civilistas, que estudian el Derecho desde un sistema conceptual que trata de lograr cada vez más en la hermeticidad, y la sistemática. Esta hermeticidad será la que logrará en última instancia la creación del sistema mismo.

La construcción de una teoría general unitaria del Derecho procesal en España, pasará por una formación más bien ecléctica del mismo, en un sentido bien extenso de la palabra, y no quedará circunscrita a la sola recepción del procesalismo italiano. Algunos de los elementos que hemos estado viendo hasta aquí, son parte de ese recorrido que de alguna manera modela una elaboración sistemática del mismo Derecho procesal de forma distinta a la de esa dogmática civilística que va de la mano del estudio de la relación jurídico-procesal o la teoría de la acción.

De Niceto Alcalá-Zamora y Castillo es la primera propuesta de una teoría general unitaria del Derecho procesal en lengua castellana. Para poder tener elementos más cercanos a cómo se llega a una exposición de este tipo, vamos a profundizar en algunas cuestiones formativas del joven estudioso, quien a todas luces, tiene como objetivo, obtener una cátedra universitaria. 
Niceto Alcalá-Zamora y Castillo obtuvo su doctorado en Derecho en el año 1928 con una tesis con el tema "El desistimiento espontáneo y el arrepentimiento

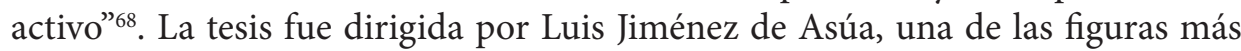
carismáticas de la penalística española de todos los tiempos y cuyos aportes al Derecho penal español son todavía llamados con insistencia por una doctrina que se empeña en tomar sus obras como importante referencia. Luis Jiménez de Asúa, no resultará acaso un paréntesis de poca importancia en el pasaje español de la procesalística científica y aún cuando no he encontrado en ningún lugar una referencia a la cuestión que propongo, no me parece descabellado hacer esta relación.

Según consta en los documentos referentes a Luis Jiménez de Asúa en los archivos de la Junta para la Ampliación de Estudios, sabemos que el profesor estudió en Francia, Suiza y Alemania. Terminados sus estudios en París, se trasladó el 2 de Enero de 1914 a Ginebra. En Suiza profundizó estudios de Doctrinas del Derecho penal y codificación. Allí cursó Derecho penal con el Profesor Alfredo Gautier, siguió un curso sobre «Imputabilidad» con el docente M. Paul Logoz y otro de M. Sottile, sobre «Legislación penal comparada». Tuvo ocasión también de estudiar Psicología (principalmente Psicología infantil) con el profesor Claparède. Señala el mismo Asúa que consagró gran parte de su tiempo "a trabajar en la Biblioteca anexa a la Universidad, rica en obras jurídico-penales y donde se encuentra abundante material."

En su estancia en Ginebra terminó su trabajo sobre «La recompensa como prevención general. El Derecho Premial». Señala que dedicó preferente atención al estudio del antreproyecto de Código penal federal guiado por los profesores Mercier, Thormann, Zürcher y Haffer. De regreso en Alemania se trasladó a Berlín y asistió a los cursos del profesor James Goldschmidt y trabajó al lado del Profesor von Liszt.

La experiencia con Franz von Liszt será fundamental para Asúa, pues lo acercará mucho a una idea que resultará tan llamativa a Asúa que la lleva consigo a España para recibir aplausos por ella. Esta propuesta que tanto eco y glorias le ganó se trataba del texto que presenta a la Junta para la Ampliación de Estudios como resultado de su estancia de investigación en el estranjero: "La unificación del Derecho Penal en Suiza. El Derecho Penal del porvenir".

Este texto posee una importante carga en cuanto representa la solución de Asúa para dar a conocer un intenso trabajo que se está llevando a cabo en un contexto Europeo por la unicidad del Derecho penal a través de la Unión Internacional del Derecho Internacional. Sin pretender una profundización en el estudio del rol de la Unión en el desarrollo de la cultura jurídica española, cuestión por demás, que excede con creces el espacio del tema del que nos preocupamos, sin lugar a dudas hay unas cuestiones que no pueden pasar desapercibidas. A partir del año 1914, se trazó el programa de trabajo de la asociación para, según declaran, los venideros próximos 20 años. En el primer punto de los acuerdos 
señalan que se preocuparán por: "como debe, en principio, ser reformado el procedimiento penal para adaptarlo al contenido del derecho penal moderno"...

Claro que esta unidad del Derecho penal de la que estamos hablando no es la misma unidad del Derecho procesal penal de la cual se habla por esos días en Italia. El esfuerzo unionista de von Liszt, no irá encaminado a la consolidación científica del Derecho penal por la vía de una dogmática jurídica, sino que será el concepto de "fin" en el Derecho penal el que otorgará una suerte de herramienta sobre la cual construir un especial sistema distinto a aquel técnico de la dogmática. Aquella unidad del Derecho penal está orientada en un sentido eminentemente práctico para el estudio comparado:

L'Union internationale de droit pénal, avec la vigueur de sa jeunesse et son ardeur au travail, pouvait-elle rencontrer une tâche plus belle et plus grande que d'essayer de faire, pour le droit de tons les pays d'Europe, ce que M. Stooss avait entrepris et déjà parachevé à cette époque, dans la partie la plus difficile, pour les cantons de la Suisse? Quand même notre but éloigné nétait pas lélaboration d'un Code pénal européen (j’espère pouvoir démontrer que cette idée n'est point une utopie ainsi qu'elle pourrait le paraître à première vue), une étude comparative du droit pénal de l'Europe, prise en ellemême, devait être d'une valeur inestimable pour quiconque dans la sphère d'action duquel rentre le droit pénal. Non seulement pour le législateur, appelé â donner à son peuple un nouveau Code pénal national et qui à cet effet voudrait mettre à profit tous les progrès et expériences faits dans d'autres pay ${ }^{69}$.

Luego veremos que ideas tan lejanas sobre unidad alrededor del Derecho, en España hallan una amalgama que perdura hasta nuestros días.

Debemos tener presente que resultará para el joven profesor Luis Jiménez de Asúa aquella unidad del Derecho penal, una experiencia que se transformará en vocación entusiasta ${ }^{70}$. No debería ser extraño que en fecha tan temprana como los años 20, o sea en fecha reciente de haber participado de aquella experiencia junto al profesor von Liszt, la propuesta del "Derecho penal del futuro" formase parte esencial de sus exposiciones docentes. Esto quiere decir que durante el tiempo en el que el profesor Asúa enseñaba en su cátedra de Madrid, todavía muy cercana a su experiencia con el profesor Von Liszt, el jovencísimo Niceto AlcaláZamora y Castillo recibía las lecciones de quien sería su profesor guía.

Para esa fecha, la difusión de la obra de una figura principalísima de la Scuolacomo esFlorian es a todas luces importante entre los penalistas españoles. Una idea de esta situación lo podemos constatar en las traducciones que se vierten al castellano de materiales y libros del mismo Florian, quedando constancia de ello al menos en las siguientes obras: Teoría psicológica de la difamación: Estudio sociológico-jurídico, 1902; De los hechos punibles y de las penas en general, 1919; Tratado de derecho penal, 1919; Parte general del derecho penal, 1929. 
Al mismo tiempo que Luis Jiménez de Asúa vive la experiencia en la que entra en contacto con el profesor Franz Von Liszt, en España se está difundiendo el pensamiento de la Scuola Italiana di Diritto positivo.Muchos importantes materiales de la Scuolacircularán en los ambientes académicos españoles, sobre todo a partir de algunos Bolonios que regresaban de estudiar del colegio Florentino. De cualquier manera, la recepción de la Scuolapositiva italiana se caracteriza por el carácterheterogéneo de la misma. La recepción en territorio ibérico de la scuola, vinculada esencialmente a los estudios criminalisticos, encontrará especiales circunstancias que influirán en un proceso de recepción, adaptación y adecuación a las necesidades españolas. Tengamos presente, como ejemplo sintomático, que la figura que es generalmente reconocida como fundamental difusor de la Scuola en el ambiente académico ibérico, Pedro Dorado Montero, al regresa a España de su estancia en el colegio de los Bolonios, trae consigo la impronta de aquella scuola italiana, que se hallará en medio de la fortísima influencia que está ejerciendo el krausismo en la vida académica, cuestión que permitirá dirigir la mirada no solo al marco italiano, sino la búsqueda de otros horizontes y esto es lo que ocurre sobre todo con una figura muy cercana a Pedro Dorado Montero que es Constancio BernaldoQuiróz quien no solo analiza críticamente la Scuola, (restando valor a los planteamientos antropométricos), sino que será quien apoya al profesor Asúa para que vaya a hacer sus estudios en Alemania y Austria, confiando quizás que se trata de un carácter y personalidad que podría influir mucho en la renovación de los estudios españoles.

En efecto, ya cuando el muy joven Niceto Alcalá-Zamora y Castillo concluya sus estudios de grado en la UniversidadCentral, este amasijo de teorías e idealizaciones, conforman un núcleo de lo más revolucionario de la penalística italiana, pero al mismo tiempo, se está asistiendo a una recepción crítica de todo este pensamiento en el que la amalgama con otras tendencias, no resultará una cuestión extraña. En ese entonces ya Alcalá-Zamora y Castillo es un estrecho colaborador del profesor Asúa. El vínculo de Niceto con Jiménez de Asúa y los más importantes miembros de aquella renovación penalística española no solo se expresa en hechos particulares, (como ser llamado a colaborar de manera cercana, no solo en la cátedra, sino además en la Comisión Jurídica Asesora,) sino que luego de comenzar la larga diáspora española posterior a la guerra civil, encontraremos muchos signos de los vínculos entre estos estudiosos que no se desvanecerían. La mayoría de estos personajes, entrarán en desgracia por sus filiaciones políticas al ser simpatizantes o parte activa del bando perdedor de la contienda de la Guerra Civil Española. Será Luis Jiménez de Asúa, quien gestionará para Niceto AlcaláZamora y Castillo (y por ende, contribuyendo al socorro del depuesto Presidente de la República,) la posibilidad de ser parte del Instituto de Derecho penal en Buenos Aires, que será la residencia de toda la familia Alcalá-Zamora por un buen tiempo. Luego Alcalá-Zamora y Castillo partiría hacia México, por la propuesta de ser parte de un muy interesante proyecto que nacía en aquel momento: el Instituto de Investigaciones Jurídicas de la UNAM. ${ }^{71}$. Volviendo a la década del 20 
del siglo XX, podemos afirmar que en ese entonces, el profesor Jiménez de Asúa, había identificado a Niceto, como un alumno con particulares aptitudes y lo tenía como su discípulo.

El primer interés de Niceto Alcalá-Zamora y Castillo fue por la penalística como él mismo nos señala: "Mi vocación inicial fue la de penalista, según revela mi tesis doctoral acerca de "El desistimiento espontáneo y el arrepentimiento activo" (1928), tema que me fue sugerido por mi inolvidable maestro y director de ella Luis Jiménez de Asúa"72. Este interés fue prontamente reemplazado por el Derecho procesal. Este reemplazo se debe a la voluntad expresa de alcanzar una cátedra universitaria dadas"las mayores perspectivas que con vistas a unas oposiciones relativamente próximas ofrecían el Derecho procesal, me llevaron a orientarme hacia él"73.

Algunos años más tarde Niceto recordaría la estrategia que debió adoptar para poder obtener aquella cátedraseñalando que la vía para el acceso a su cátedra era la de emprender el camino a través de la escritura de monografías. El sabía que el camino de las referencias, y la guía de algún profesor del ramo, para él estaban selladas y la presentación de publicaciones, ya en ese entonces formaba parte de los requerimientos formales que podían ser exigidos para el acceso a la cátedra universitaria.

A todas luces decidirse por el Derecho procesal, resultaba la opción más inteligente para quien pretendiera acceder a una cátedra universitaria española pues en la asignatura existía de manera general un número elevado de profesores de edad avanzada, que seguramente necesitaría un próximo remplazo generacional. Producto de esta situación, ya había podido acceder a la cátedra, por ejemplo, un personaje tan representativo e importante como Francisco Beceña, el cual aún perdiendo un concurso para ocupar una cátedra, la obtuvo sin problema en las segundas oposiciones. Incluso, había una cátedra de Derecho procesal que llevaba largos años sin ser ocupada por nadie. Esta cátedra que al parecer a nadie gustaba quizás por lo periférica respecto a la centralidad de Madrid, Barcelona, o Salamanca, era la cátedra de la Universidad de Santiago de Compostela la cual había sido ocupada por un período de aproximadamente 30 años por Luis Zamorano Carrete, quien falleció en 1918 siendo profesor en activo de su respectiva cátedra. A pesar de haberse declarado un concurso de traslado para ocupar la plaza, nadie pretendió el puesto del profesor anterior y se abrió entonces el mecanismo de las oposiciones para ocupar la vacante. Así es como Matías Domínguez Ballarín, resultó el ganador de unas oposiciones donde además había participado el nombrado Beceña que obtuvo 2 votos contra los 3 que obtenía el ganador. Por Real Orden de 10 de abril de 1921 fue otorgada la cátedra a DominguesBallaría, que solo permaneció en su cátedra por pocos meses, pues por concurso de traslado, se mudó a la universidad salmantina. Desde aquella fecha la cátedra se encontraba vacante todavía en los primeros días de 1932. 


\subsection{Una cátedra como meta y una idea por defender; la preparación de niceto para obtener la cátedra de Derecho procesal de Santiago de Compostela}

Es por eso que un año después de haber obtenido el Doctorado en Derecho en 1928, ya comenzará Niceto Alcalá-Zamora y Castillo a publicar distintos trabajos especializados en el tema procesal.

Sobre la manera en la que se produce la consolidación de la formación procesalistas de Niceto, no podemos hallar muchos elementos sino es a través de sus escritos, pues no he encontrado ninguna referencia a simpatías académicas o relaciones con otros colegas que se dedicaran a la disciplina. En 1929 aparecerá la primera publicación de Niceto en la Revista General de Legislación y Jurisprudencia, se trata del artículo Lo que debe ser el Ministerio Público. Este primer material de Niceto, está muy en sintonía con un trabajo anterior de Beceña que había publicado el mismo 1929: Magistratura y Justicia.

Para el próximo año Niceto presenta en dos entregas "Los recursos en nuestras leyes procesales" en la Revista crítica de Derecho Inmobiliaria, este trabajo, se puede tener como un importante momento de la formación procesalística de Niceto, pues por el tema de los recursos, pasará aquella institución que vimos que es la casación española, en la que dará el espacio a la exégesis sin código y, el tema del estudio de los recursos en la legislación española. Este último tema resulta muy interesante en es sentido de constatar el nivel de dispersión doctrinal, normativa, y falta de sistemática en los estudios del Derecho procesal español.

Ese mismo año aparece el primer libro de Niceto Alcalá-Zamora y Castillo escrito a cuatro manos con el padre. El hecho de publicar un libro junto con el padre, seguramente tendrá alguna repercusión en el ambiente académico, pues Niceto Alcalá-Zamora y Torres (el padre) es una figura pública de visibilidad absoluta, y el año sucesivo será proclamado primer presidente de la Segunda República española. Creo que esta sola situación ya va a garantizar de por si, que Niceto Alcalá-Zamora y Castillo sea un joven al menos un poco más visible que el resto de sus contemporáneos, cuestión que se pondrá de relieve con posterioridad cuando el mismo Niceto no obtendrá la mayoría de los votos en las oposiciones cátedras de la Universidad de Zaragoza. La cuestión de cuan conocido fuese por ese entonces el joven Niceto, puede resultar de interés para la valoración de cómo se percibió posteriormente aquellas oposiciones.

Un comentario sobre estas oposiciones caben en este momento, pues resulta que aquellas oposiciones gozaron de un halo de ejemplaridad, toda vez que en la misma el ganador Leonardo Prieto Castro, resultaba una figura que a la historia ha quedado como "el desconocido que le ganó al hijo del Presidente de la República”. En realidad el joven Leonardo Prieto Castro, podía resultar menos 
desconocido para los profesores que fueron miembros de los tribunales de las oposiciones que el mismo Niceto como veremos luego.

Regresando a las publicaciones de Niceto, tenemos que el libro con el que inicia la actividad más seria Alcalá-Zamora y Castillo, y que ha elaborado junto al padre, lleva el mismo nombre que el famoso trabajo de Chiovenda "La condena en costas procesales", que además, ese mismo año aparecería traducido al Español y con amplia introducción del profesor de Barcelona, Xirau. No creo que fuera del conocimiento de Niceto la próxima aparición del libro ese mismo año, pues resultaba, cuanto menos riesgoso, presentarse con un textohomónimo y sobre un tema alrededor del cual el maestro absoluto de la disciplina había casi comenzado su apostolado. Este episodio quizás sea una muestra de la desconexión de Niceto Alcalá-Zamora y Castillo con el ambiente académico procesal español y esta fue una infeliz coincidencia en la que aquella obra a cuatro manos quedará relegada a un plano muy secundario.

Esta desconexión a la que me refiero no creo debamos buscarla en el desconocimiento de los intereses y motivaciones de los procesalistas españoles de la época, pues ya desde el primer material que había presentado Niceto, había mostrado que había sabido escoger en manera que fuese coherente con los temas de mayor actualidad, pero insisto en que muy probablemente faltara un vínculo personal directo con los procesalistas representantes del nuevo procesalismo para España.

En febrero de ese mismo año, Niceto hace solicitud a la Junta para la Ampliación de Estudios de una beca para estudios de Derecho procesal en Alemania. ${ }^{74}$ Estos estudios de Derecho procesal serán de gran importancia para el joven procesalista pues hasta aquel momento la formación de Niceto se había basado, primero en el curso de Derecho procesal que había recibido en su paso por la universidad, y luego por el estudio autodidacta hurgando entre lo más actual del tema que quizás pudiera percibir en las publicaciones especializadas, artículos y textos de los profesores de la materia desde España. Sabemos ya que el procesalismo italiano que circulaba entre en el entorno español, era fundamentalmente el que se percibía a través de los pioneros Xirau y Beceña, y por lo tanto se trataba de una recepción fundamentalmente civilística.

No obstante esta circunstancia, es muy probable que Niceto estudiara en este período de intenso desarrollo procesal civilístico para España, la obra del penalista Florian, que ya el joven conocía de algunas traducciones de sus obras al castellano y que desde 1919 contaba con una traducción al castellano de su Tratado de Derecho procesal. Este tratado será importante pues es la primera referencia en idioma español al importante debate que nos hemos referido con anterioridad sobre la unidad teórica del Derecho procesal. Quizás aquella mismo orfandad académica de Niceto le permitió no circunscribir su mirada a un procesalismo que a todas luces estaba poniendo mucha más atención al virtuosismo dogmático de la técnica procesal-civilística. Esta misma orfandad, permitirá que Niceto, 
teniendo como referente todavía la tan rica experiencia formativa con su maestro Asúa, busque sin prejuicios en una obra producida por un penalista, claves de estudio y teorías para profundizar sus estudios.

Esta posibilidad de ir a buscar por el Derecho procesal penal, elementos de estudio al procesalismo en desarrollo no resultará raro si tenemos en cuenta que Niceto llegará de un ambiente de gran riqueza en el debate doctrinal penalístico, y que además, como ya vimos con anterioridad, en la academia española enseñar Derecho procesal, no hacía una distinción entre Derecho procesal civil y penal. Con estos antecedentes, nada más normal que Niceto tomara el libro de un personaje tan relevante como Florian, como referente de estudio para ciertas cuestiones procesales. Por esta razón me atrevo a afirmar que sea Florian y no Chiovenda, Calamandrei o Beceña, quien sea la puerta de entrada definitiva de Niceto por la disciplina del Derecho procesal y las reflexiones sobre una teoría general unitaria del Derecho procesal. Esta suposición puedo además sustentarla en una peculiaridad del texto que Niceto propondrá alas oposiciones a cátedras para la cátedra de la universidad de Santiago, Estudio acerca del concepto, método, fuentes y programas del Derecho procesal. ${ }^{75}$ En este texto que referenciamos, Florian es el referente doctrinal que será mas insistentemente citado ${ }^{76}$.

Otro elemento que me sirve para sustentar la idea del valor de una visión cercana a procesalistas vinculados con el Derecho penal, resulta de la misma solicitud que hiciera el joven Niceto a la Junta para la Ampliación de Estudios. ${ }^{77}$ En el escrito de solicitud deberá señalar cuales son sus intereses en la beca que solicita, y allí nuestro autor señalará un muy específico tema que tiene interés en estudiar: "los derroteros del Enjuiciamiento criminal del futuro". Como tema, resultará cuanto menos discordante con la tendencia civilística imperante y nos invita a suponer alguna relación con aquel "Derecho penal del futuro" (que trata el tema de la unidad del Derecho penal en Suiza, unidad institucional, jurisdiccional, política) de Asúa y con el debate sobre la unidad del Derecho procesal (unidad dogmática, técnica) que se asoma en la presentación de Tratado de Florian. Antes ya habíamos visto que el debate italiano, había adquirido fuerza teniendo como referente la doctrina Mortariana de unidad jurisdiccional, que para Niceto era presentada ante sí como resultado de una encrucijada muy particular, que seguramente no tendrá la oportunidad de vivenciar ningún otro procesalista español de su época: reunido en un nudo gordiano las dos unidades necesarias, para que se pretenda ir a la construcción sistemática de aquella tan sugerida unidad del Derecho procesal. Sin embargo en este momento de la solicitud a la beca, Niceto no hace alusión ninguna respecto a una exposición de este tipo.

Continuando con la experiencia de la estancia de estudios en Alemania, que le fue finalmente concedida, queda una importante valoración por hacer pues luego de esta estancia, la formación procesalística de Niceto, concluirá definitivamente por estar marcada por aquel método técnico-jurídico que distinguirá lo que será llamado "escuela científica del Derecho procesal" y que está señado por el desarrollo de los conceptos que llegan de la civilística de 
raigambre Savigniana. Lo que me interesa dejar establecido con esta observación es que es poco probable que el conocimiento de la obra de Florian, se deba a un momento posterior a la experiencia de estudio en Alemania, donde el contacto con el profesor Kisch, lejano de Florian, marcará de manera honda la continuidad de sus estudios procesales. Para Niceto aquella oportunidad tuvo un gran valor pues, de no contar con un interlocutor con el que pudiese intercambiar sus dudas e inquietudes, pasó a contar con una de las figuras de primer orden en el Derecho procesal europeo. En las relaciones de Niceto con su profesor Kisch, además de la profunda admiración que ganó el profesor en las conferencias, llegó auna afinidad más íntima que permitió el intercambio de ideas y proyectos en espacios más íntimos. Tenemos suficientes elementos que nos sirven para considerar la impresión del profesor Kisch sobre Niceto.

El primero de estos elementos será la dedicatoria de Niceto al profesor de Munich del trabajo investigativo que presentó a la Junta para la Ampliación de Estudios como resultado de su estancia en Alemania ${ }^{78}$, dicha investigación representa el material que debía presentar por la conclusión de la estancia de estudios por la beca otorgada. El trabajo tendrá un componente histórico importante pues se trata de la recuperación al debate académico de la época de una notable figura española del siglo XVII ${ }^{79}$, y muy probablemente fuese sugerido por el mismo Kisch si tenemos en cuenta que se vincula con el trabajo de este profesor en el Derecho concursal y aún más con las investigaciones del mismo sobre las fuentes del Derecho procesal alemán. La investigación en cuestión versa sobre Francisco Salgado de Somoza y en específico, sobre el valor de esta figura en la conformación de lo que se considera el Derecho concursal moderno. El resultado de la investigación aparecerá en un volumen que se dió a conocer con el nombre de "Un español mal comprendido: Salgado de Somoza, en la literatura alemana sobre concurso de acreedores. ${ }^{80 "}$

La dedicatoria de este texto señala: "Al profesor Guillermo Kisch, de Munich, con la admiración, gratitud y afecto de su primer discípulo español." Estas líneas nos ofrecen dos lecturas. Si asumimos que Niceto al querer remarcar con ser el "primer discípulo" del profesor Kisch señalar ser el primer español en asistir de manera asidua a clases del profesor de Derecho procesal y concursal de Munich, debemos remarcar que esta afirmación es del todo inexacta, pues existe la constancia de que al menos el profesor Gabriel Bonilla Marín, en una estancia de estudio en Alemania patrocinada por la misma Junta para la Ampliación de estudios, había asistido entre los años 1922 y 1923 a clases de Derecho procesal con el mismo profesor Kisch. ${ }^{81}$ Pero si hacemos una interpretación más estrecha (y quizás más ajustada) de lo que ser discípulo representa, entonces quizás si se ajuste a la razón, pues evidentemente la huella del profesor Kisch sobre la posterior producción de Niceto es notable; cuestión que sin duda no fue asumida así por Bonilla, al menos no de manera pública y confesada...

Aquella declaración de Niceto estaría marcando un fuerte mensaje a los catedráticos españoles, fuerte mensaje quizás expresado no de manera implícita, 
pero que seguramente no pasó desapercibido a quien pretendiese sentar una escuela española de Derecho procesal: el joven procesalista no reconocería en ningún procesalista español el horizonte principal de aquel trabajo suyo. No quedó aquí esta desconexión cada vez más explícita con la guía de profesores españoles ya que en la misma presentación de su Estudio acerca del concepto, método, fuentes y programas del Derecho procesal, Kisch, será el único referente metodológico-pedagógico en la enseñanza del Derecho procesal ${ }^{82}$.

Claro que este asunto tampoco pasó sin ser notado por el tribunal calificador en las oposiciones a la cátedra de Derecho procesal de Santiago. En efecto, el profesor Juan Serra Puig, señaló en uno de sus informes sobre el trabajo de Niceto que "En cuanto al fondo son dispensables, pero no justificables su exagerada devoción al profesor Kisch ${ }^{83}$..."

Otro elemento que nos demuestra el acercamiento de Niceto con el profesor Kisch, lo tendremos por el conocimiento de Alcalá-Zamora sobre particularidades de la vida privada del profesor que deja plasmada en la nota necrológica que dedicará Niceto al morir el profesor de Munich, donde señala por ejemplo, que Kisch se comunicaba con familiares en su casa de Munich no en idioma alemán sino que "hablaba habitualmente en francés, con tan absoluta corrección y tan impecable acento, que sólo fijándose en su inconfundible tipo alemán (ojos, cabellos, corte de cabeza, inclusive el modo de vestir) cabía descubrir la nacionalidad del conversante". ${ }^{44}$ Además del tiempo dedicado por Niceto a participar de las conferencias del profesor de Derecho procesal, el resto del tiempo lo dedica a la investigación.

Los temas históricos no resultarán lejanos a Niceto, pues al menos en su núcleo familiar, las inquietudes por temas históricos pueden hallar un hilo de desarrollo por el cercano vínculo con Rafael Ureña y Smenjaud una figura clave en la actualización científica del pensamiento jurídico español de inicios del siglo. Niceto Alcalá-Zamora y Torres, había sido asistente de Ureña en la universidad. La literatura jurídica, que fue así mismo una de las asignaturas claves en el proceso de recuperación histórica de la asignatura, dejó una profunda huella tanto en el futuro presidente de la República, como en Niceto Alcalá-Zamora y Castillo, cuestión facilmente comprobable en algunos de los materiales que luego escribirán ambos donde se hace especial atención a la relación de la literatura con el Derecho ${ }^{85}$. La educación que promueve Ureña, de clara orientación Institucionista, tiene los ojos puestos en la cultura alemana. Obra de Ureña, el Museo-Laboratorio, pasa a ser un proyecto clave de esta experiencia renovadora, donde el componente histórico de los estudios jurídicos jugará un papel de gran centralidad. Incluso en fecha reciente al viaje de Niceto a Alemania, se había desarrollado una polémica al interno de la cátedra de Historia de la Literatura jurídica española cuando esta se transformó al interno de la carrera de Derecho, en una Ciencia política. El tema de la historia de la literatura jurídica era de gran interés en la época, en cuyas reflexiones halla Niceto una idea que repetirá varias veces: “...para conocer a fondo el pensamiento jurídico español, más útil que una Cátedra (enseñanza) es 
un Laboratorio (investigación), porque mal se puede explicar lo que se ignora, y la literatura jurídica en España permanece en gran parte desconocida u olvidada, abandono que permita a los extraños ocuparse a su antojo de nuestros escritores y sentar afirmaciones equivocadas con frecuencia, que adquieren, sin embargo, autoridad de cosa juzgada, al no ser destruidas por quienes más obligados están a ello." ${ }^{36}$ Afirmación que nos traerá de regreso aquella leyenda negra española que tan pesadamente viven los intelectuales españoles sobre todo a partir del famoso artículo sobre España que apareció en la EncyplodédieMéthodique. ${ }^{87}$ La convicción de la necesidad de la recuperación de la historia de la literatura jurídica española seguramente será un gran incentivo a Niceto, que se encuentra ante la posibilidad de reivindicar con esta figura, no solo el Derecho de su patria, sino que representa una reafirmación de orgullo nacional.

El estudio del Labyrinthus para Niceto, representará cerrar un ciclo formativo importante. Como habíamos visto anteriormente, la experiencia que llega de la penalistica y la dogmática procesal-civilística, aportan dos visiones posibles sobre una sistematización del Derecho procesal. Ahora este ejercicio completará un recorrido ideal, en el cual encontraremos no solo un soporte político y técnico a una teorización doctrinal: en este momento Niceto se ha puesto el reto de dar un hilo conductor a un tema de connotación procesal en una recuperación histórica que puede ofrecer valor al intento de obtener íconos que permitan el total abandono español del Labyrinthus institucional del antiguo régimen.

Niceto parte del presupuesto de que es Francisco Salgado de Somoza, quien muy probablemente "se encuentra en la fase culminante en la evolución del concurso" basándose en un pequeño Grundriss des deutschenKonkursrechts de su maestro Kisch, donde solo aparece el nombre de Salgado de Somoza en la parte referente a los antecedentes históricos.

En efecto el libro que está estudiando Niceto es de gran valor, y quizás todavía no puesto de relieve en toda la connotación que el mismo tiene y no solo para el estudio del Derecho concursal, porque representará un material de simbolismo especial en el nacimiento de una doctrina jurídica moderna. Niceto destaca como el libro de Salgado y Somoza, tuvo gran éxito en aquellas ciudades europeas ${ }^{88}$ donde el desarrollo económico hacía de la institución de la quiebra, parte del instrumental necesario para el desarrollo de las relaciones comerciales. Aquel Labyrinthus, que trató de tender un hilo en la práctica de los tribunales europeos, representó además, la "primera obra sistemática sobre el concurso" ${ }^{89}$ Este estudio de Niceto sobre un tema como el que se propone, es coherente con la necesidad de buscar los referentes españoles de una modernidad que urgentemente debe adaptarse a un contexto europeo que ha superado lo que en España sigue siendo un fuerte impedimento a su desarrollo cultural: el hecho de existir elementos de gran poder político y cultural que se empeñan en mantener como principal referente de la nacionalidad un entramado simbólico-cultural perteneciente al antiguo régimen. Creo firmemente que representa este escrito la definitiva aprehensión 
por parte de Niceto de un método de estudio definitivamente alejado, ya no solo de manera ideológica, sino también instrumental, del conservadurismo feudalizante.

El carácter sistematizador de la obra de Salgado de Somoza en un sentido conclusivo para su época, no pasará por alto ante las recientes lecturas de Niceto que revelan la lucha de otra sistematización contemporánea a él. Muy probablemente el estudio de aquella sistematización del Labyrinthus medieval en la construcción de un Derecho concursal, ahora halla nuevas luces en la voluntad sistematizadora que para un Derecho procesal, Niceto había visto crecer ante sí ya como un ente unitario. De estas experiencias no será dificil llegar a la necesidad de sistematizar lo que para Niceto, representa ya una realidad fáctica y que solo necesitaba una orgánica exposición.

Al regresar Niceto a España, se apresura a publicar algunos pequeños escritos para contar con el mayor soporte posible a su pretensión de concursar por una plaza de Derecho procesal que ha quedado vacante de improviso, (pero no demasiado inesperadamente,) pues el titular de la cátedra de Derecho procesal para la facultad de Derecho en Zaragoza, falleció ese mismo año aún encontrándose en ejercicio.

De los dos últimos artículos que publica Niceto y que presentará al tribunal para las próximas oposiciones, Un grave problema judicial y político: $\mathrm{La}$ justicia municipal y La ética profesional y el régimen jurídico de las corporaciones forenses, el primero de ellos también nos dice de la preocupación del joven procesalista por la unidad al interno del ordenamiento judicial español. En este artículo hay una valoración de tipo política, que es el reflejo de una preocupación importante en la política española y que forma parte del gran problema de lo nacional en el Estado moderno español. Esta preocupación en el futuro tendrá un más enérgico tratamiento por parte de Niceto, cuando ya siendo profesor de Derecho procesal en la universidad de Zaragoza, impartirá algunas conferencias sobre las función del Tribunal de Garantías Constitucionales, texto por el cual luego será reclamado como el padre del procesalismo moderno en el ámbito del Derecho procesal..$^{90}$ Sobre el trabajo referente a la ética profesional, podemos decir que de alguna manera, será también el prólogo de un tema sobre el que volverá el profesor en otras muchas más ocasiones y nace de su convicción de la necesidad del espíritu corporativo al interno del ambiente académico para aunar fuerzas en proyecto de largo alcance ${ }^{91}$.

En 1932 ocurren las oposiciones a la cátedra de la Universidad de Santiago. Esta será la oportunidad en la cual por vez primera ocurre en idioma castellano, y quizás en cualquiera otra lengua una propuesta de sistematización desde el procesalismo científico de toda la disciplina del Derecho procesal en un sentido unitario. 


\section{ALGUNAS CUESTIONES QUE NO QUIERO DEJAR DE SEÑALAR}

El Derecho procesal se encuentra en un proceso que podríamos nombrar de "reacomodo estructural". Este proceso de reacomodo tiene como características.

1. El establecimiento de un paradigma epistemológico con una clara enunciación de principios, fuentes (formales e históricas) y metodología.

2. El asentamiento del Derecho procesal como rama específica que pretende un espacio central dentro del ordenamiento. (A partir sobre todo de la idea del Derecho procesal como un Derecho "garantista".).

3. La división en especiales categorías, que reclaman ser parte del Derecho procesal como específica rama del Derecho pero que al mismo tiempo pretenden una particularidad que singulariza el fenómeno de estudio. (Sobre todo últimamente el Derecho procesal constitucional, en otras ocasiones ha sido la famosa división entre Derecho procesal civil y Derecho procesal penal, y en otras ocasiones, Derecho procesal laboral, etc...).

En este estudio he profundizado en el primero de los puntos señalados, donde he resaltado algunas cuestiones que han contribuido a llegar a la situación actual en el estudio del Derecho procesal como fenómeno "científico".

La figura de Niceto Alcalá-Zamora y Castillo resulta fundamental en este recorrido de la llamada ciencia del Derecho procesal y con una importancia aún mucho mayor para el Derecho procesal producido en lengua castellana.

El profesor Niceto Alcalá-Zamora y Castillo, fue influenciado por algunas circunstancias personales y otras relacionadas con el medio en el cual se desarrolló su formación jurídica primeramente y luego de manera específica, en el Derecho procesal.

Dentro de estas circunstancias la primera que he resaltado es la particular manera en la que se desarrolló el estudio del Derecho procesal en la universidad española. He destacadocomo en la universidad española de fuerte tradición medieval, el estudio del Derecho procesal se desarrolló unitariamente como elemento ritual y formal de comportamiento ante los distintos fueros, sin dar cabida a otras concepciones (como sí ocurría por ejemplo en Italia).

Un elemento que es notable es el de la influencia de la revolución francesa, no solo a través de los elementos ideológicos que introducirá en toda la sociedad europea, sino por el influjo que tuvo el fenómeno de la codificación que le sobrevino.

Sin lugar a dudas las discusiones sobre la diversidad o unidad del Derecho procesal, (otra vez, una discusión exclusivamente italiana), será el punto de 
partida de un debate que tendrá una larga extensión temporal, y al cual aún hoy se le dedican congresos y reuniones de especialistas.

Pero como punto final, quiero resaltar como para el caso de Niceto Alcalá-Zamora y Castillo, la ideación del Derecho procesal unitario, también estará matizado por la impronta unionista del Derecho procesal que a inicios del siglo XX se desarrolló sobre todo a partir de la obra del profesor alemán Franz von Liszt y algunos de sus más destacados discípulos españoles (especialmente el profesor de Derecho penal de Niceto: Luis Jiménez de Asúa.

\section{NOTAS}

1 En el volumen 40 de los Quadernifiorentini per la storia del pensierogiuridico moderno, del 2011, la profesora española Marta Lorente Sariñena hace referencia a algunas de las características de este pasaje epocal para la cultura jurídica española, haciendo hincapié en la "falta de una cultura de código" y el especial desarrollo de la doctrina en la jurisprudencia española. M. LORENTE SARDiÑas, "La doctrina legal y el silenciamiento de los juristas en una España sin código. (1808-1889)", QuaderniFiorentini per la storia del pensierogiuridico moderno., 2011.

2 Estudios sobre la universidad española con especial énfasis en los estudios jurídicos los encontramos en los trabajos investigativos del profesor Martínez Neira. Especialmente útil resulta El estudio del derecho. Libros de texto y planes de estudio en la universidad contemporánea. M. Martínez Neira, El estudio del derecho. Libros de texto y planes de estudio en la universidad contemporánea., Editorial Dykinson, Universidad Carlos III de Madrid, 2001.

3 Sobre este período coincidente por demás con el desarrollo de la cultura barroca, resulta importante el texto de Luis Enrique Rodríguez-Sans Pedro Bezares, La Universidad salmantina del Barroco. L. E. Rodríguez-San Pedro Bezares, La Universidad salmantina del Barroco, periodo 1598-1625. (2 T), Universidad de Salamanca, 2005.

4 Carta al doctor Prado de la Universidad de Oviedo. Sobre el método de estudiar el Derecho. G. M. Jovellanos, Obras de Don Gaspar Melchor de Jovellanos, P. Mellado, 1845, pág. 485.

5 M. P. Alonso Romero, Salamanca, escuela de juristas, Editorial Dykinson, S.L., 2012, pág. 399.

6 L. E. Rodríguez-San Pedro Bezares, La Universidad salmantina del Barroco, periodo 15981625.Tomo II, Universidad de Salamanca, 2005, pág. 509. y M. P. Alonso Romero, Salamanca, escuela de juristas, cit., pág. 401.

7 Compartiendo totalmente la propuesta de las comunidades imaginadas de Anderson. B. Anderson, Imagined Communities : Reflections on the Origin and Spread of Nationalism, Verso, 1991.

$8 \mathrm{Al}$ respecto ver P. J. L. OrTIZ, "El proceso en los reinos cristianos de nuestra Reconquista antes de la recepción romano-canónica”, Anuario de historia del derecho español, 14, 1943, pág. 185.

9 Para el análisis de los textos y manuales en la enseñanza del Derecho, me apoyo en el trabajo del profesor Martínez Neira. M. Martínez Neira, El estudio del derecho. Libros de texto y planes de estudio en la universidad contemporánea., cit.

10 Entre el siglo XVIII y XIX, tendremos el gradual pasaje entre aquella práctica forense hacia el desarrollo de una rama específica procesal. Un vistazo a los manuales requeridos en los planes de estudio nos dibuja esta situación:

Bach, Johann August, HistoriaJurisprudentiaeromanae, Lispsiae, 1754, 1754 (49). Beccaria, Cesare, Tratado de los delitos y de las penas, Madrid, 1774. (46, 47, 48, 49). Blair, Hugh, Lecciones 
de retórica, 4 vol, Madrid, 1816. (46,47, 48, 49). Enciso Castrillón, Félix, Lecciones y modelos de elocuencia sagrada y forense, 2 vol, Madrid 1838. $(46,47,48,49)$. Pedro Gomez de la Serna y Juan Manuel Montalbán, Tratado académico forense de los procedimientos judiciales, 3 vol, Madrid, 1848-1853. 2da Ed. Madrid 1856. (49, 50, 51, 52, 53, 54, 55, 56, 58, 61, 64, 67). Gutierrez, José Marcos, Práctica criminal de España, 3 vol, Madrid, 1804-1806. 5ta ed 1828. (47,48,49). Lackics, GeorgiusSigismundus, Praecognitia iuris eclesiaticiuniversi opera, Valencia, 1788, Madrid 1822, $(46,47,48,49)$. Ortiz de zuñiga, Manuel, Elementos de práctica forense, 2 vol, granada, 1841, 43 y 51 $(46,47,48,49,50,51,52,53,54,55)$. --- Práctica general forense, Granada, 1856, (56, 58, 61, 64, 67). Peláez del Pozo, Julián, Tratado teórico y práctico de la orgacización, competencia y procedimientos en materia contencioso administrativas, Madrid, 1848 (49). Pérez Anaya, Francisco, Lecciones y modelos de elocuencia forense, 4 vol, Madrid, 1848-1849 (49). Quiliano, Marco Fabio, Instituciones oratorias, 2 vol, Madrid, 1799 (47, 48, 49). Rodríguez, Juan María, Instituciones prácticas o curso elemental completo de práctica forense, 4 ta ed. 2 vol, 1855-1856 (49, 50, 51, 52, 53, 54, 55, 56, 58, 61, 64, 67). Sáinz de Andino, Pedro, Elementos de elocuencia forense, 2 vol, Madrid, 1828, 3era ed, 1839, 4ta ed 1847, (46, 47, 48, 49). Saurí y Lleopart, Ramón, Elocuencia forense, Barcelona, 1847, (48, 49). Tapia, Eugenio de, Elementos de jurisprudencia mercantil, 2 ed, Valencia, 1845.1846. $(46,47,48,49,50,51,52,53,54,54,55,56,58)$.---, Febrero o librería de jueces, 10 vols, Madrid, 1846, (46, 47, 48, 49). Verlanga Huerta, Fermín, Jurisprudencia popular. Comprende los negocios de menos cuantía, Madrid 1838. 2 ed, 1840 (49), Tratado que continuando la jurisprudencia popular sobre pleitos de menos cuantía comprende el procedimiento de los demás negocios civiles de la jurisdicción ordinaria, 2 vol, Madrid, 1841 (49).

En esta lista de textos, los números entre paréntesis corresponde a los años en los que ese texto, fue utilizado como parte del plan de enseñanza. Ibid., págs. 13-117.

11 Ibid., págs. 119-318.

12 En el siglo XIX español, las tres guerras civiles conocidas como Guerras Carlistas marcarán de manera profunda las relaciones que se establecen para el desarrollo o freno de proyectos culturales y sociales. Aunque en esencia los bandos en oposición fuesen los carlistas absolutistas, y los isabelinos liberales, esta distinción no será homogénea en la manera en la que ambos bandos contendientes proponen construcciones institucionales y culturales para el país. Ejemplo de esto último ocurre cuando con la proclamación de la Primera República Española, en febrero de 1873, muchos de los isabelinos, pasaron a ser carlistas.

13 Marañón, transmitiría ese espíritu en su Elogio y nostalgia de Toledo, asumiendo la España deseada como tolerante, amante de las ciencias y la cultura en general. Distinta por cierto, de un próximo proyecto de España deseada, excluyente y que dominó el imaginario de "lo español" durante el siglo XX, continuación sin embargo de la decadencia espiritual española en un contexto en el cual se proyectan y luchan entre sí, especialmente en España dos tendencias políticas totalitarias: comunismo y fascismo y que se representa perfectamente en aquel "Canto a la España deseada" de Manuel Machado, de sentido profundamente anti-liberal. Colmeiro, José F. Memoria Histórica e Identidad Cultural: De la Postguerra a la Postmodernidad, Anthropos Editorial, 2005, pág. 44.

14 R. Porras Quiroga, Compendio histórico del Derecho civil de España: con la cronología de los Reyes desde la fundación de la monarquía de los godos hasta el actual reinado de Isabel II., Imp. de la Viuda e Hijos de Compañel, 1836, pág. 191. El autor continúa señalando "Sin dudas que de esta diversidad de códigos, e inmensidad de leyes procede el estado obscuro, confuso, y aún contradictorio de nuestra legislación".

15 Varios son los trabajos del profesor español Carlos Petit en el que hace referencia a esta cuestión. A mi entender son indispensables algunos artículos suyos.C. Petit Calvo, "El Código inexistente (I): Por una historia conceptual de la cultura jurídica en la España del siglo XIX", Anuario de derecho civil, vol. 48, 4, 1995, fecha de consulta 29 septiembre 2012, ; C. Petit Calvo, "España y el CodeNapoléon", Anuario de Derecho Civil, vol. LXI, 2008; C. Petit Calvo, "Tríptico ovetense: la Universidad en el cambio de siglo", Cuadernos del Instituto Antonio de Nebrija de Estudios sobre la Universidad, vol. 13, 2, 2010, fecha de consulta 29 septiembre 2012. 
16 Como institución de cimera importancia, está la Junta para la Ampliación de Estudios e Investigaciones Científicas, vinculada estrechamente con el movimiento krausista español (resultado directo de las gestiones de destacados krausistas). La misma junta patrocinó una serie de instituciones, centros de estudios y laboratorios que lograron un gran impacto en el desarrollo de la vida cultural española. Entre las organizaciones vinculadas a la junta tenemos la Residencia de Estudiantes, el Centro de Estudios Históricos, el Museo Antropológico, el Museo de Ciencias Naturales, el Real Jardín Botánico Nacional y el Instituto Nacional de Ciencias Físico-Naturales.

17 A. H. Serrano, "El Krausismo español y la cuestión nacional”, Enrahonar: quaderns de filosofía, $16,2006$.

18 N. Alcalá-Zamora y Torres, "La unidad del Estado y la diversidad de sus legislaciones civiles", Revista General de Legislación y Jurisprudencia, vol. 144, 1924.

19 N. Alcalá-Zamora y Torres, Las mancomunidades provinciales: Discurso pronunciado en el Congreso el 28 de junio de 1912., 1912; El regionalismo y los problemas de Cataluña, 1916; El Estatuto Catalán: Necesidad de discutirlo. Discurso en el Congreso de los Diputados. 1919, 1919. Los datos los obtengo de la tesis de doctorado de Derecho, por la Universidad Complutense de Madrid, de P. Pascual Martínez, "Escritores y editores en la Restauración Canovista" en 1995. El autor señala la bibliografía de Niceto Alcalá-Zamora y Torres hasta el año 1923 y como curiosidad puedo señalar que al referirse a Niceto Alcalá-Zamora y Torres, lo hace como Aniceto, además de que en ningún lugar hace alusión a que se tratase del futuro presidente de la Segunda República.P. Pascual Martínez, "Escritores y editores en la Restauración canovista. (1875-1923)", 1995, Universidad Complutense de Madrid, Madrid, España. En realidad el "descubrimiento" de Niceto Alcalá-Zamora y Torres como figura central, resulta relativamente reciente. El bando vencedor de la guerra civil logró que un gran silencio se levantara alrededor de la realidad de la época republicana, solo recientemente se han hecho públicos los diarios personales del primer Presidente de la República (y el único legítimamente proclamado), que han servido para interesantes re-lecturas de la historia de este período. Los estudios histórico-jurídicos alrededor de la figura, que seguramente serían muy interesantes, son nulos.

$20 \mathrm{Y}$ en efecto, hoy el profesor Carlos Petit, nos puede asegurar con toda tranquilidad, que "en el momento de determinar su objeto el historiador del concepto de código se encuentra exonerado de la carga de la pruba."C. Petit Calvo, "El Código inexistente (I)", cit., pág. 50.

21 Como veremos luego esta oposición en España queda muy al descubierto en la contraposición entre krausistas (y luego institucionistas) y los antikrausistas o conservaduristas.

22 El holismo aristotélico en la especial interpretación de la Iglesia Católica que sobre todo a partir de Santo Tomás lleva a cabo el rescate de la cultura filosófica clásica, sirve para soportar y argumentar la centralidad de Dios como ente organizante y perfecto, del cual una oposición a algún postulado del dogma establecido puede representar al status quo, una crítica al sistema de saberes establecido. La debilidad superior del dogma católico fue encomendar su relación con el acceso al saber a un pretendido sistema perfecto.

23 C. Petit Calvo, “España y el CodeNapoléon”, cit., págs. 1774-1775.

$24 \mathrm{Al}$ respecto además de los artículos vistos, hay una historiografía especializadad en el tema, de la cual quisiera destacar La codificación del Derecho civil en España: (1808-1889) del profesor de la Universidad de Cantabria Juan Baró Pazos. J. BARó Pazos, La codificación del derecho civil en España: (1808-1889), Ed. Universidad de Cantabria, 1993.

25 Ver los comentarios de Carlos Petit en su C. Petit Calvo, "El Código inexistente (I)", cit. Quien señala: “...basta con afirmar que el déficit de código en la España del siglo XIX se compensa con un superávit de derecho jurisprudencial. Late aquí, si se quiere, la vieja tradición no legislativa del iuscommune, aunque se reformula ahora el papel de la doctrina. A partir de la introducción en España del recurso de nulidad los comentaristas más relevantes resultan ser los jueces, en particular los magistrados del órgano de casación" 
26 J. Delgado Castro, "La historia de la casación civil española: una experiencia que aconseja no avanzar en el modelo de unificación de la doctrina", Revista de derecho (Valparaíso), 33, 2009, fecha de consulta 1 octubre 2012.

27 A. Furetière, Dictionnaireuniversel, contenantgénéralementtous les motsfrançoistantvieux que modernes et les termes de toutes les sciences et des arts, 1690, pág. Parlement.

28 La Constitución de 1812, fue promulgada por las Cortes Generales de España en Cádiz el 19 de marzo de 1812. De corte liberal, se trata de la primera constitución española y tuvo aplicación en reducido espacio del territorio ibérico por la división debido a la invasión napoleónica y las juntas interinas localistas. Estuvo vigente hasta el 4 de mayo de 1814 tras la restauración de Fernando VII.

29 J. Delgado Castro, "La historia de la casación civil española", cit., pág. 352.

30 J. M. M. y Navarro, Observaciones sobre el recurso de casación en España, Imp. de la Revista de Legislación, 1860, pág. 7.

31 J. de Castro y Orozco, “Exámen de recurso de casación en España”, en Revista de jurisprudencia: Ciencia.-Literatura.-Variedades, La Habana, 1859, pág. 320.

32 C. Petit Calvo, "El Código inexistente (I)", cit., pág. 80.

33 Ibid., pág. 61.

34 Un acercamiento al fenómeno del krausismo español que debe ser tenido en consideración es el realizado por Gonzálo Capellán de Miguel G. CAPellán DE Miguel, "La renovación de la cultura española a través del pensamiento alemán: Krause y el krausismo”, Brocar: Cuadernos de investigación histórica, 22, 1998.

35 Ibid., págs. $145-146$.

36 “Comentario a: Curso de Derecho Natural o de filosofía del derecho.", La Censura, 10, 1845, pág. 76.

37 G. M. Jovellanos, Obras de Don Gaspar Melchor de Jovellanos, cit., pág. 487.

38 El modelo Canovista, que ve la luz a partir de la restauración de la monarquía de Alfonso XII, hijo de Isabel II, se puede resumir como un intento conciliador de institucionalización moderna en una dificilmentemodernizable cultura política de raigambre monárquica y católica. Para la educación el compromiso con el conservadurismo representaba esencialmente garantizar la supremacía de la Iglesia en la educación y el alejamiento de élites disidentes a esta política de la participación en la vida docente e investigativa a través del Decreto Orovio de 1875. Al respecto ver M. MARTínez NeIRA, El estudio del derecho. Libros de texto y planes de estudio en la universidad contemporánea., cit.

39 Quiero destacar en este sentido, la oposición entre un sistema del cual es imposible reconocer sus límites, pues son los límites del saber de Dios, a otro sistema que el hombre estudia y establece sus límites para conocerlo.

40 Savigny no parece un desconocido en un selecto grupo de juristas españoles, seguramente aquellos vinculados a la Institución de Libre Enseñanza. En 1869 habia nacido la Comisión española de la Fundación Savigny en Barcelona. Nota 1 en SAVIGNY, F.K VON, Sistema del derecho romano actual, tomo I, F. Góngora, 1878. pp. xviii.

41 Manuel Duran y Bas en, F. K. von Savigny, Sistema del derecho romano actual, 1, F. Góngora, 1878, pág. xxi.

42 Ibid., pág. xxvii.

43 Podemos por ejemplo hacer un análisis cuantitativo de la cantidad de solicitudes de becas que se hicieron a la Junta para la Ampliación de Estudios. El resultado es que los destinos para estudios de Derecho solicitados fueron, primeramente Francia con 70 becas otorgadas, Alemania con 65 
becas, Suiza con 43, Bélgica con 28, Reino Unido con 27, Italia con 19, Estados Unidos con 15 y 2 becas para Portugal, una sola beca fue dirigida a países latinoamericanos en el año 1913 (Argentina, Uruguay, Chile y Bolivia). Los datos los obtengo de los Archivos de la Junta para la Ampliación de Estudios.

44 Se impone un estudio concienzudo de las historias nacionales con sus relaciones con la circulación de las corrientes de pensamiento. Enfoques de estudios historiográficos en este sentido han sido desarrollados sobre todo en algunos países considerados periféricos en la producción de saber científico (España, Argentina, México). En la cultura española, los antecedentes más llamativos al respecto los tenemos en los estudios de historia de las ideas de Marcelino Méndez Pelayo. Una reflexión sobre el flujo de las ideas en el entorno jurídico español no ha sido desarrollado en profundidad hasta ahora. Estudios semejantes han sido llevados a cabo sobre todo por estudiosos del pensamiento económico. En tal sentido, resultan interesantes los trabajos del economista ErnestLlunch alrededor de las "historias nacionales del pensamiento". En un reciente texto que reúne algunos ensayos del economista español (quien fuera asesinado por un miembro de ETA en el año 2000) podemos encontrar recientes acercamientos a la propuesta de Lluncs. FundacióErnestLluch, En la estela de ErnestLluch: ensayos sobre historia del pensamiento económico, 1aed, Gobierno de Aragón, Departamento de Presidencia : FundacióErnestLluch, Zaragoza, 2006.

45 Ver nota 19.

46 Que dejó de estar vigente cuando es sustituída por la Ley de Enjuiciamiento Civil 1/2000 y transforma de manera radical la impartición de justicia civil española.

47 Revista general de legislación y juRisprudencia, Editorial Reus, 1914, pág. 200.

48 Aún con las referencias que el mismo Chiovenda hace de su deuda con la procesalística alemana del siglo XIX.

49 En muchos escritos de Niceto durante su vida de procesalista confirma esta história, pero quizás cuando quedará definitivamente expuesta en un hilo conductor coherente de inicio a fin es en Estudios de teoría general e historia del proceso este material de 1974 reúne en un solo volumen mucha e importante información sobre la evolución del Derecho procesal. Sobre todo ver el capítulo que titula "Momentos, figuras, preocupaciones y tendencias del procesalismo italiano" pp. 501-546. N. Alcalá-Zamora y Castillo, Estudios de teoría general e historia del proceso (1945-1972), Dirección General de Publicaciones, Universidad Nacional Autónoma de México, Mexico 29, D,F., 1974.

50 F. Cipriani, Storie di processualisti e di oligarchi, GiuffrèEditore, 1991; IlCodice di proceduraciviletragerarchi e processualisti, Edizioniscientificheitaliane, 1992.

51 P. Calamandrei, Lettere 1915 - 1956, La Nuova Italia, 1968, págs. 204-205.

52 J. XirauPalau, "Le condizioniattuali del processocivile in Ispagna", Rivista di dirittoprocessualecivile, 1925.

53 F. Cipriani, Storie di processualisti e di oligarchi, cit.

54 M. Cachón Cadenas, Historias de procesalistas, universidades y una guerra civil (1900-1950), cit., pág. 286.

55 varios, Studi in onore di Federico Cammeo, A. Milani, 1933.

56 P. Calamandrei, Opere giuridiche: Problemi vari e ricordi di giuristi ; Arringhe e discorsi di politica legislativa, vol. X, Morano, 1976, pág. 46.

57 J. Chiovenda, La condena en costas, Librería General de Victoriano Suárez, 1928, pág. 13.

58 M. Pescatore, La logica del diritto, 2 ed, UTET, Torino, 1883, pág. 5.

59 L. Mattirolo, Trattato di dirittogiudiziariocivile italiano, 1902, pág. 21. 
60 Sobre este tema y del mismo autor hay dos textos que deben ser consultados: M. Meccarelli, Le Corti di Cassazionenell'ItaliaUnita: ProfiliSistematici e Costituzionalidellagiurisdizione in una prospettivacomparata (1865-1923), A. Giuffrè, Milano, 2005. y el material que aparece en el número 36 del año 2007 de los QuaderniFiorentini.M. Meccarelli, "Giuridizionepenale e legalitànelpensiero di LodovicoMortara.", QuaderniFiorentini per la storia del pensierogiuridico moderno., 36, 2007. El profesor Meccarelli, que se ha ocupado con detenimiento en el tema de la casación italiana entre el siglo XIX y el XX, ofrece rica información no solo sobre las repercusiones fácticas de los fenómenos que estudia, sino que nos deja abundante instrumental para poder razonar sobre esta experiencia para la Italia liberal.

61 L. Ferrara, "Ildirittopubblico e ilprivatonelnostroattualeprocessocivile., IlFilangieri, 1905. Este trabajo conoció una segunda edición solo algunos meses después como un folleto separado, editado por Societàeditricelibraria de Milano. El trabajo es sumamente interesante pues nos ofrece una mirada del Desarrollo del Derecho procesal italiano en un momento germinal y cuando no está consolidada la leyenda de Chiovenda, por lo cual puede constituir una referencia sobre como se presenta al estudioso del tema procesal, el hilo conductor de una ciencia del Derecho preChiovendana. De cualquier manera, Chiovenda mismo permanece desde entonces muy presente pues ya se conocían sus trabajos esenciales de entonces, que son citados como referente de autoridad, en ocasiones para confirmar valoraciones de Mortara.

62 L. LuCchini, Elementi di procedurapenale., G. Barbèra, Firenze, 1908, pág. 1,2..

63 G. Battaglini, “Dirittopenale e politicacriminale”, RivistaPenale, vol. LXXXI, 1915.

64 F. Cipriani, Storie di processualisti e di oligarchi, cit., pág. 94 y siguientes.

65 Cuya manifiesta adhesión a la tradición penalística positivista, permitirá una encuadratura coherente en ella (no perfecta, pues no es un fenómeno equivalente el positivismo penal y la política penal fascista, aún cuando sirva aquella a la política de esta). Al respecto recordemos la exclusión de Norberto Bobbio de la existencia de una cultura fascista, cuestión que comparte de manera general Ferrajoli con la distinción de la necesaria construcción del sistema institucional fascista que indiscutiblemente se levanta al unísono del poder político, pues no se puede divorciar política y derecho. Sin embargo el punto distintivo de la producción de "iniciativas o empresas duraderas e históricamente relevantes" no se lo podemos achacar al fascismo sino a la particular manera en la que se presenta el desarrollo de la experiencia fascista italiana, donde la tendencia técnica-jurídica logrará una integración al interno del sistema político, siendo en realidad estos (con palabras de Pietro Costa) juristas-juristas, los que con mayor fuerza enriquecerán el panorama doctrinal del Derecho en la época fascista.

66 U. Pergola, L'Istruttoriadeiprocessipenalisecondoilnostrocodice di procedurapenale, 1922.

67 M. SbricColi, “La penalisticacivile. Teorie e ideologie del dirittopenalenell' Italia unita., en Storia del dirittopenale e dellagiustizia, vol. II, GiuffrèEditore, Milano Italy, 2009, pág. 539.

68 N. Alcalá-Zamora y Castillo, El desistimiento espontáneo y el arrepentimiento activo., Colegio Nacional de Sordo-Mudos y de Ciegos de Madrid, Madrid, 1928.

69 F. Von LiszT, La législation pénale comparée, O. Liebmann, 1894, pág. XII.

70 A Luis Jiménez de Asúa lo encontraremos con gran dedicación trabajando junto con el profesor argentino Francisco CarsiZacarés y luego con el chileno Eduardo Novoa Montreal en la elaboración del primer código penal tipo latinoamericano a partir de 1962. En aquella ocasión, los objetivos de dicha unificación del Derecho penal latinoamericano, no se alejaba al menos en cuanto a su enunciación a lo que se había plasmado en la Unión Internacional de Derecho Penal por Liszt.

71 Allí se radicaría hasta su regreso a España ya en pleno tránsito a la democracia.

72 N. Alcalá-Zamora y Castillo, Estudios de teoría general e historia del proceso (1945-1972),

2, Dirección General de Publicaciones, Universidad Nacional Autónoma de México, Mexico 29, D,F., 1992, pág. I. 
73 Ibid.

74 Archivos de la Junta para la Ampliación de Estudio, Expediente correpondiente a Niceto AlcaláZamora y Castillo, accesible en la dirección www.archivojae.edaddeplata.org/jae_app/

75 N. Alcalá-Zamora y Castillo, "Estudio acerca del concepto, método, fuentes y programas del Derecho procesal".

76 En el escrito que presentó Niceto al Tribunal de las oposiciones para el acceso a la cátedra de Derecho procesal de la facultad de Derecho de Santiago de Compostela, o sea en su escrito de Estudio acerca del concepto, método, fuentes y programas de Derecho procesal, el profesor Florian encabezará la lista de autoridades doctrinales más ampliamente citadas, estando presente en 21 de las 160 páginas que tiene el escrito, solo superado por el profesor Kisch quien se encuentra presente, como veremos más adelante no solo como autoridad doctrinal, sino esencialmente metodológica.

77 Ver Archivos de la Junta para la Ampliación de Estudios, accesible on-line en http://archivojae. edaddeplata.org/jae_app/ último acceso 11-nov-2012.

78 Esta dedicatoria, por demás tiene una incongruencia que señalaré luego.

79 Tipo de trabajo este, de la recuperación de figuras notables de otras épocas, caro a los investigadores españoles, que tratan de reclamar un espacio perdido por las injusticias de la historia, heridos en el orgullo, con la consolidación de la leyenda negra española y la verdadera catástrofe del 98.

80 El nombre de este trabajo resultó alterado para su publicación de 1932, como señaló Niceto año después, el título inicial sería "Salgado de Somoza en la literatura alemana sobre concurso de acreedores", a lo cual se le agregó quizás con motivos editoriales, como si de una novela se tratase "Un español mal comprendido", pero la alteración más importante de las que padeció la edición de esta obra, fue la mutilación de algunos pasajes al interno del texto expositivo. Años después, la investigación de Niceto sobre Salgado de Somoza, fue impresa nuevamente, esta vez seguida mucho más de cerca por su autor, y sanjados los problemas que aquejaron a la primera edición. Ver $\mathrm{N}$. Alcalá-Zamora y Castillo, "Salgado de Somoza y los concursalistas alemanes., en Ensayos de Derecho Procesal: Civil, Penal Y Constitucional, Edición de la Revista de jurisprudencia argentina, Buenos Aires, 1944.

$81 \mathrm{Al}$ respecto se puede constatar la información que aparece en el archivo de Gabriel Bonilla Marín en los archivos de la JAE.

82 Niceto utilizará otro referente que será además español, pero no es ninguno de los profesores de la disciplina de Derecho Procesal, sino su cercano y querido profesor de Derecho Penal, Luis Jiménez de Asúa.

83 M. CaChón Cadenas, Historias de procesalistas, universidades y una guerra civil (1900-1950), cit., pág. 422.

84 N. Alcalá-Zamora y Castillo, Derecho Procesal en serio y en broma., Editorial Jus, México, D.F. Escuela Libre de Derecho, 1978, pág. Nota Necrológica Kischpp 101.

85 Una de las obras memorables del Niceto (padre) Alcalá-Zamora y Torres conciste exactamente en aquella en la cual se refiere al pensamiento del Quijote visto por un abogado, N. AlCALÁ-ZamorA Y Torres, El pensamiento de "El Quijote" visto por un abogado, G. Kraft, 1947. o aquella otra en la que se dedica a relaciones entre el teatro y el Derecho en la obra del dramaturgo Juan Ruiz de Alarcón, N. Alcalá-Zamora y Torres, El derecho y sus colindancias, en el teatro de don Juan Ruiz de Alarcón, Impr. Universitaria, 1949. Como ejemplo de las preocupaciones en temas más generales sobre la cultura española, tendríamos también algunos escritos de Niceto (padre) que podrían dar fe de ello, como sus Estudios sobre la ciencia española en el siglo VII, N. Alcalá-Zamora Y Torres, Estudios sobre la ciencia española del siglo XVII, Gráfica Universal, Madrid, 1935. De Niceto (hijo), también podemos dar fé de una estrecha vinculación entre el estudio del Derecho y de la Historia. Creo que la prueba más consistente al respecto es una mirada a su producción doctrinal 
en general, donde el tema histórico ocupa siempre un espacio muy central. No acaso, el mismo Niceto, y quizás sin proponérselo, ha servido como uno de los autores fundamentales para forjar una cierta historia del Derecho procesal, que es la que el mismo plasma en sus escritos. Además que debemos tener en consideración los numerosos escritos dirigidos exclusivamente a tratar temas implícitamente o explícitamente históricos, así tenemos por ejemplo Trayectoria y contenido de una teoría general del proceso, donde señala "La historia del Derecho Procesal en particular, de igual manera que la Historia del Derecho en general, es, por su finalidad y por su técnica, ciencia histórica y no jurídica"N. Alcalá-Zamora y Castillo, Estudios De Teoría General e Historia del Proceso, cit., pág. 508. en la que claramente se posiciona como historiador al intentar ofrecer su visión de la historia de la ciencia que él mismo estudia.

86 N. Alcalá-Zamora y Castillo, "Salgado de Somoza y los concursalistas alemanes.", cit., pág. 64 Esta reflexión la repetirá Niceto en numerosas ocasiones a lo largo de su carrera.

87 Aujourd'hui le Danemark, la Suède, la Russie, la Polognemême, l'Allemagne, l'Italie, l'Angleterre et la France, tous ces peuplesennemis, amis, rivaux, tousbrûlentd'unegénéreuseémulationpour le progrès des sciences et des arts! Chacunmédite des conquêtesqu'ildoitpartageravec les autresnations; chacund'eux, jusqu'ici, a faitquelquedécouverteutile, qui a tournéauprofit de l'humanité! Mais que doiton à l'Espagne? Et depuisdeuxsiècles, depuisquatre, depuis dix, qu'a-t-elle faitpourl'Europe?Este famoso fragmento del artículo de la EncyclopédieMéthodique, escrito por Masson de Morcilliers, causó una crisis entre España y Francia. A todas luces el artículo publicado en 1782, resultó profundamente hiriente dentro de la comunidad hispánica, que sobre todo aquella ilustrada, había puesto especial atención en la labor de los enciclopedistas.

88 Amberes, Venezia, Frankfurt, Lyon.

89 N. Alcalá-Zamora y Castillo, “Salgado de Somoza y los concursalistas alemanes., cit., pág. 77.

90 Quien ha defendido esta tesis con mayor fuerza en fecha reciente es el profesor mexicano Eduardo Ferrer Mac-GregorPoisot, quien presenta la tesis, (sugerida antes por otros autores latinoamericanos,) en el artículo Alcala-Zamora y el Derecho Procesal Constitucional y lo hace parte del libro Derecho Procesal Constitucional: origen Científico (1928-1956) de 2008, material que luego será traducido al italiano y publicado por la Universitàdeglistudi di Bologna en el 2009E. Ferrer Mc-Gregor, Derecho Procesal Constitucional: origen Científico (1928-1956), Marcial Pons, Madrid, 2008.

91 Quizás donde más claro quedaría plasmado esto será en la misma actividad de Niceto AlcaláZamora en el Instituto de Investigaciones Jurídicas de la UNAM.

\title{
Referencial Bibliográfico
}

\author{
A. Furetière, Dictionnaireuniversel, contenantgénéralementtous les \\ motsfrançoistantvieux que modernes et les termes de toutes les sciences et des arts.
}

B. ANDERSON, Imagined Communities : Reflections on the Origin and Spread of Nationalism, Verso, 1991.

BACH, Johann August,„HistoriaJurisprudentiaeromanae, Lispsiae, 1754, 1754 (49).

BARÓ PAZOS. J. BARó PAzos, La codificación del derecho civil en España: (1808-1889), Ed. Universidad de Cantabria, 1993.

BECCARIA, Cesare, Tratado de los delitos y de las penas, Madrid, 1774. (46, 47, 48, 49). 
BLAIR, HUGH, Lecciones de retórica, 4 vol, Madrid, 1816. (46,47, 48, 49).

C. Petit Calvo, "El Código inexistente (I): Por una historia conceptual de la cultura jurídica en la España del siglo XIX”, Anuario de derecho civil, vol. 48, 4, 1995, fecha de consulta 29 septiembre 2012.

C. Petit Calvo, "El Código inexistente (I)”, cit.

C. Petit Calvo, “España y el CodeNapoléon”, Anuario de Derecho Civil, vol. LXI, 2008;

C. Petit Calvo, “Tríptico ovetense: la Universidad en el cambio de siglo", Cuadernos del Instituto Antonio de Nebrija de Estudios sobre la Universidad, vol. 13, 2, 2010, fecha de consulta 29 septiembre 2012, .

COlmeiro, José F. Memoria Histórica e Identidad Cultural: De la Postguerra a la Postmodernidad, Anthropos Editorial, 2005.

E. Ferrer Mc-Gregor, Derecho Procesal Constitucional: origen Científico (1928-1956), Marcial Pons, Madrid, 2008.

ENCISO CASTRILLÓN, Félix, Lecciones y modelos de elocuencia sagrada y forense, 2 vol, Madrid 1838. $(46,47,48,49)$.

F. CIPRIANI, Storie di processualisti e di oligarchi, cit.

F. CIPRIAnI, Storie di processualisti e di oligarchi, GiuffrèEditore, 1991; IlCodice di proceduraciviletragerarchi e processualisti, Edizioniscientificheitaliane, 1992.

F. Von Liszt, La législation pénale comparée, O. Liebmann, 1894.

G. Capellán de Miguel, "La renovación de la cultura española a través del pensamiento alemán: Krause y el krausismo”, Brocar: Cuadernos de investigación histórica, 22, 1998.

G. M. Jovellanos, Obras de Don Gaspar Melchor de Jovellanos, P. Mellado, 1845.

Gutierrez, José Marcos, Práctica criminal de España, 3 vol, Madrid, 1804-1806. 5ta ed 1828. $(47,48,49)$.

J. Delgado Castro, "La historia de la casación civil española: una experiencia que aconseja no avanzar en el modelo de unificación de la doctrina", Revista de derecho (Valparaíso), 33, 2009, fecha de consulta 1 octubre 2012,

J. Chiovenda, La condena en costas, Librería General de Victoriano Suárez, 1928, pág. 13.

J. de Castro y Orozco, “Exámen de recurso de casación en España”, en Revista de jurisprudencia: Ciencia.-Literatura.-Variedades, La Habana, 1859.

J. Delgado Castro, “La historia de la casación civil española”, cit., pág. 352. 
J. M. M. y NAVARro, Observaciones sobre el recurso de casación en España, Imp. de la Revista de Legislación, 1860.

J. XirauPalau, "Le condizioniattuali del processocivile in Ispagna”, Rivista di dirittoprocessualecivile, 1925.

L. E. Rodríguez-San Pedro Bezares, La Universidad salmantina del Barroco, periodo 1598-1625. (2 T), Universidad de Salamanca, 2005.

L. Mattirolo, Trattato di dirittogiudiziariocivile italiano, 1902..

Lackics, GeorgiusSigismundus, Praecognitia iuris eclesiaticiuniversi opera, Valencia, 1788, Madrid 1822, (46, 47, 48, 49).

M. Cachón Cadenas, Historias de procesalistas, universidades y una guerra civil (19001950).

M. Lorente SARdiñas, "La doctrina legal y el silenciamiento de los juristas en una España sin código. (1808-1889)", QuaderniFiorentini per la storia del pensierogiuridico moderno., 2011.

M. Martínez NeIra, El estudio del derecho. Libros de texto y planes de estudio en la universidad contemporánea., Editorial Dykinson, Universidad Carlos III de Madrid, 2001.

M. P. Alonso Romero, Salamanca, escuela de juristas, Editorial Dykinson, S.L., 2012.

M. Pescatore, La logica del diritto, 2 ed, UTET, Torino, 1883.

M. Sbriccoli, "La penalisticacivile. Teorie e ideologie del dirittopenalenell' Italia unita., en Storia del dirittopenale e dellagiustizia, vol. II, GiuffrèEditore, Milano Italy, 2009.

N. Alcalá-Zamora y Castillo, "Estudio acerca del concepto, método, fuentes y programas del Derecho procesal”.

N. Alcalá-Zamora y Castillo, "Salgado de Somoza y los concursalistas alemanes., en Ensayos de Derecho Procesal: Civil, Penal Y Constitucional, Edición de la Revista de jurisprudencia argentina, Buenos Aires, 1944

N. Alcalá-Zamora y Castillo, Derecho Procesal en serio y en broma., Editorial Jus, México, D.F. Escuela Libre de Derecho, 1978, pág. Nota Necrológica Kischpp 101.

N. Alcalá-Zamora y Castillo, El desistimiento espontáneo y el arrepentimiento activo., Colegio Nacional de Sordo-Mudos y de Ciegos de Madrid, Madrid, 1928.

N. Alcalá-Zamora y Castillo, Estudios de teoría general e historia del proceso (19451972), Dirección General de Publicaciones, Universidad Nacional Autónoma de México, Mexico 29, D,F., 1974. 
N. Alcalá-Zamora y Castillo, Estudios de teoría general e historia del proceso (19451972), 2, Dirección General de Publicaciones, Universidad Nacional Autónoma de México, Mexico 29, D,F., 1992.

ORTIZ DE ZUÑIGA, Manuel, Elementos de práctica forense, 2 vol, granada, 1841, 43 y $51(46,47,48,49,50,51,52,53,54,55)$. ---, Práctica general forense, Granada, 1856, (56, $58,61,64,67)$.

P. Calamandrei, Lettere 1915 - 1956, La Nuova Italia, 1968.

P. Calamandrei, Opere giuridiche: Problemi vari e ricordi di giuristi; Arringhe e discorsi di politica legislativa, vol. X, Morano, 1976.

P. J. L. ORTIz, "El proceso en los reinos cristianos de nuestra Reconquista antes de la recepción romano-canónica”, Anuario de historia del derecho español, 14, 1943.

PEDRO GOMEZ DE LA SERNA Y JUAN MANUEL MONTALBÁN, Tratado académico forense de los procedimientos judiciales, 3 vol, Madrid, 1848-1853. 2 da Ed. Madrid 1856. (49, 50, 51, 52, 53, 54, 55, 56, 58, 61, 64, 67).

PELÁEZ DEL POZO, Julián, Tratado teórico y práctico de la orgacización, competencia y procedimientos en materia contencioso administrativas, Madrid, 1848 (49).

PÉREZ ANAYA, Francisco, Lecciones y modelos de elocuencia forense, 4 vol, Madrid, 1848-1849 (49).

QUILIANO, Marco Fabio, Instituciones oratorias, 2 vol, Madrid, 1799 (47, 48, 49).

R. Porras Quiroga, Compendio histórico del Derecho civil de España: con la cronología de los Reyes desde la fundación de la monarquía de los godos hasta el actual reinado de Isabel II., Imp. de la Viuda e Hijos de Compañel, 1836.

RODRÍGUEZ, Juan María, Instituciones prácticas o curso elemental completo de práctica forense, 4 ta ed. 2 vol, 1855-1856 (49, 50, 51, 52, 53, 54, 55, 56, 58, 61, 64, 67).

SÁINZ DE ANDINO, Pedro, Elementos de elocuencia forense, 2 vol, Madrid, 1828, 3era ed, 1839, 4ta ed 1847, $(46,47,48,49)$.

SAURÍ Y LLEOPART, Ramón, Elocuencia forense, Barcelona, 1847, (48, 49). Tapia, Eugenio de, Elementos de jurisprudencia mercantil, 2 ed, Valencia, 1845.1846. (46, 47, $48,49,50,51,52,53,54,54,55,56,58)$.---, Febrero o librería de jueces, 10 vols, Madrid, $1846,(46,47,48,49)$.

U. Pergola, L'Istruttoriadeiprocessipenalisecondoilnostrocodice di procedurapenale, 1922.

VARIOs, Studi in onore di Federico Cammeo, A. Milani, 1933.

VERLANGA HUERTA, Fermín, Jurisprudencia popular. Comprende los negocios de menos cuantía, Madrid 1838. 2 ed, 1840 (49), Tratado que continuando la jurisprudencia popular sobre pleitos de menos cuantía comprende el procedimiento de los demás negocios civiles de la jurisdicción ordinaria, 2 vol, Madrid, 1841 (49). 


\section{Resumen}

Este artículo pretende hacer algunas reflexiones a partir de la construcción histórica de la Teoría General del derecho procesal en el ámbito hispanoamericano. En esta propuesta, se analizarán los elementos que fueron importantes en esa construcción, partiendo del análisis de la tradición española en la enseñanza de esa materia hasta la consolidación del proceso.

Palabras-clave: Teoría General del Derecho Procesal. Construcción Histórica. Hispanoamericano. 


\section{SOBRE A HISTÓRIA GERAL UNITÁRIA DO DIREITO PROCESSUAL, ALGUNS ELEMENTOS A SEREM LEVADOS EM CONTA PARA UMA HISTÓRIA DA DISCIPLINA PARA O ÂMBITO HISPANO-AMERICANO}

\section{Resumo}

Este artigo pretende tecer algumas reflexões a partir da construção histórica da Teoria Geral do direito processual no âmbito hispano-americano. Nessa proposta, analisar-se-á os elementos que foram importantes nessa construção, partindo-se da análise da tradição espanhola no ensino dessa matéria até a consolidação do processo.

Palavras-chave: Teoria Geral do direito processual. Construção Histórica. Hispanoamericano. 


\title{
ABOUT THE UNITARY GENERAL HISTORY OF THE PROCEDURAL LAW, SOME ELEMENTS TO BE TAKKEN IN CONSIDERATION FOR A HISTORY OF THE DISCIPLINE FOR THE HISPANIC-AMERICAN SCOPE
}

\begin{abstract}
This article aims to make some reflections from the historic construction of the General Theory of the Procedural Law in the Hispanic-American scope. In this proposal, will be analyzed the elements that were important in this construction, starting from the analysis of the Spanish tradition in the teaching of this subject to the consolidation of the process.
\end{abstract}

Keywords: General Theory of the Procedural Law. Historic building. Hispanic-American.

Recebido em xxxx.

Aprovado em xxxx. 